\title{
A laboratory study of anisotropic geomaterials incorporating recent micromechanical understanding
}

\author{
L.-T. Yang ${ }^{1} \cdot$ X. $\mathrm{Li}^{2} \cdot$ H.-S. Yu ${ }^{1} \cdot$ D. Wanatowski ${ }^{1,3,4}$
}

Received: 18 November 2014/Accepted: 12 November 2015/Published online: 24 December 2015

(C) The Author(s) 2015. This article is published with open access at Springerlink.com

\begin{abstract}
This paper presents an experimental investigation revisiting the anisotropic stress-strain-strength behaviour of geomaterials in drained monotonic shear using hollow cylinder apparatus. The test programme has been designed to cover the effect of material anisotropy, preshearing, material density and intermediate principal stress on the behaviour of Leighton Buzzard sand. Experiments have also been performed on glass beads to understand the effect of particle shape. This paper explains phenomenological observations based on recently acquired understanding in micromechanics, with attention focused on strength anisotropy and deformation non-coaxiality, i.e. non-coincidence between the principal stress direction and the principal strain rate direction. The
\end{abstract}

D. Wanatowski

dariusz.wanatowski@nottingham.ac.uk

L.-T. Yang

lintao.yang@foxmail.com

X. Li

xia.li@nottingham.ac.uk

H.-S. Yu

hai-sui.yu@nottingham.ac.uk

1 Nottingham Centre for Geomechanics, Faculty of Engineering, University of Nottingham, University Park, Nottingham NG7 2RD, UK

2 Department of Chemical and Environmental Engineering, University of Nottingham, University Park, Nottingham NG7 2RD, UK

3 Department of Civil Engineering, Faculty of Engineering, University of Nottingham, University Park, Nottingham NG7 2RD, UK

4 Department of Civil Engineering, Faculty of Science and Engineering, University of Nottingham Ningbo China, Ningbo 315100, China test results demonstrate that the effects of initial anisotropy produced during sample preparation are significant. The stress-strain-strength behaviour of the specimen shows strong dependence on the principal stress direction. Preloading history, material density and particle shape are also found to be influential. In particular, it was found that non-coaxiality is more significant in presheared specimens. The observations on the strength anisotropy and deformation non-coaxiality were explained based on the stress-force-fabric relationship. It was observed that intermediate principal stress parameter $b\left(b=\left(\sigma_{2}-\sigma_{3}\right) /\right.$ $\left.\left(\sigma_{1}-\sigma_{3}\right)\right)$ has a significant effect on the non-coaxiality of sand. The lower the $b$-value, the higher the degree of noncoaxiality is induced. Visual inspection of shear band formed at the end of HCA testing has also been presented. The inclinations of the shear bands at different loading directions can be predicted well by taking account of the relative direction of the mobilized planes to the bedding plane.

Keywords Anisotropy · Discrete elements · Laboratory tests $\cdot$ Numerical models $\cdot$ Plasticity $\cdot$ Sand (soil type)

\section{Introduction}

Shear strength is a fundamental soil property used in geotechnical design. Thus, it must be determined with reasonable accuracy. However, the stress-strain-strength behaviour of most sedimentary deposits is anisotropic. Soil strength is generally lower when the direction of major principal stress is farther away from the deposition direction. Hence, soil anisotropy has attracted long-lasting interest of geotechnical researchers and practitioners. 
Arthur and Menzies [3] reviewed several early studies on the soil anisotropy. They prepared samples in a tilting mould to give different directions of sample deposition with respect to the applied principal stress directions and found the specimen produced by pouring through air in one direction corresponded to a strength and prefailure stressstrain anisotropy. Various laboratory testing devices have been developed and applied to study soil anisotropy, including plane strain apparatuses [e.g. 2, 48, 63, 69], directional shear cells $[46,47,50,71]$, true triaxial apparatuses [1, 3, 39, 44, 72] and hollow cylinder apparatuses [e.g. 9, 21, 24, 32, 40, 43, 55, 59, 67, 75].

Amongst available apparatuses, the hollow cylinder apparatus (HCA) that offers independent control of the magnitudes of three principal stresses and the inclination of the major-minor principal stress axes has become most popular. Extensive phenomenological observations on soil strength and loading path dependence have been made in HCA [9, 21, 32, 40, 42, 75]. Clear evidence of material deformation non-coaxiality, an interesting phenomenon firstly reported by Roscoe et al. [53] as the non-coincidence of the principal strain rate directions and the principal stress directions, has been obtained from HCA testing [e.g. $9,21,75]$.

Although most sedimentary deposits are inherently anisotropic due to their natural deposition in horizontal layers, further anisotropy can be induced by the applied stresses or strains, i.e. by stress history. Conceptually, distinction between the two types of anisotropy (i.e. inherent and induced anisotropy) was first made by Casagrande and Carrillo [10] with the former being caused by deposition process and the latter by stress history. It is worth noting that several important studies on induced anisotropy have been carried out in conventional triaxial cells [e.g. 8, 13-17, 19, 20, 22, 25, 26, 31, $51,52,62,68]$, even though in a conventional triaxial testing only the normal and parallel orientations of the major principal stresses relative to the axes of material symmetry can be achieved. For instance, the effects of drained triaxial compression on the position of yield surface were investigated by Lade and Prabucki [31], Poorooshasb et al. [51, 52], Tatsuoka and Ishihara [62]. On the other hand, the effects of stress history on the liquefaction (or instability) behaviour of loose sands were studied, for example, by Bobei et al. [8], Di Prisco et al. [13], Doanh et al. [14-17], Gajo and Piffer [20], Ishihara and Okada [25, 26], Vaid et al. [68]. In particular, the experimental data obtained from various triaxial tests revealed the important role of stress history on the undrained behaviour of loose sands.

The effects of monotonic-drained compression preshearing on the subsequent compression undrained shearing were studied by Di Prisco et al. [13], Doanh et al. [14]. In general, their experimental results indicate that the peak stress ratio at the onset of deviatoric strain softening (or instability), in subsequent undrained shearing, is highly dependent on the effective stress ratio, $\eta$, applied in drained preshearing. The higher the $\eta$ at the end of drained preshearing, the higher the peak $\eta$ achieved in subsequent undrained shearing in the same direction.

Gajo and Piffer [20] also studied the effect of drained monotonic compression and extension preshearing on the subsequent undrained behaviour in compression and extension. They reported that the peak deviatoric resistance in undrained shearing would be increased by preshearing in the same direction but could be reduced by drained preshearing in the opposite direction.

More recently, Doanh et al. have reported in the series of their papers $[15-17,19,22]$ that drained triaxial preshearing contributes to progressive transformation of compressive and unstable behaviour of loose Hostun sand into dilative and stable behaviour, while remaining in loose state.

Majority of the experimental studies discussed above demonstrate that the undrained behaviour of sand is highly dependent on the previous type of stress history. In general, loose granular materials become less susceptible to liquefaction because of preshearing. However, these studies are limited to the analysis of undrained behaviour under axisymmetric conditions. Studies on the effects of drained preshearing on the subsequent drained shearing of sand, in particular under principal stress rotation, are limited even though most forms of geotechnical construction will inevitably lead to the rotation of principal stress axes. In such cases, it is not possible to determine the strength and deformation characteristics of the soil using conventional triaxial testing.

Based on laboratory observations, a number of advanced constitutive models have been developed, e.g. bounding surface plasticity model $[33,34,73]$, yield vertex model [64], double shearing model $[76,77]$ and yield vertex and double shearing model [74]. A state parameter [6] has been introduced in the models to quantify the effect of material anisotropy, and often for simplicity, it is assumed that material anisotropy remains unchanged during the process of loading even though induced anisotropy has been noticed as early as in 1940s [10].

During the past few decades, researchers have also been exploring the micromechanics of soil anisotropy through multi-scale investigations. It is now generally recognized that the material anisotropy is originated from particle scale as a consequence of particle spatial arrangement, also known as the internal structure. Experimental techniques including photo-elastic testing [46, 47, 49] and X-ray computer tomography $[7,61]$ have been employed to obtain particle-scale information. Computer simulations, 
mostly using discrete element methods (DEM) [12], have been used as an alternative and powerful approach to explore micromechanics along with experimental developments.

The stress-force-fabric relationship $[37,38,56]$ has also been established as an analytical linkage between the microscale observations and the continuum-scale material behaviours. Based on the 2D DEM simulations presented in $\mathrm{Li}$ and $\mathrm{Yu}$ [36], $\mathrm{Li}$ and $\mathrm{Yu}$ [38] explained the micromechanisms of strength anisotropy and deformation non-coaxiality using the established stress-force-fabric (SSF) relationship [37] by focusing on fabric, force and strength anisotropies and their evolutions during shearing. These numerical and analytical advances improved the understanding of the complicated behaviour exhibited by granular materials, although idealization of particle shapes, limitation of sample size and use of simplified contact models are inevitable.

When studying fundamental behaviour of real geomaterials, the importance of laboratory testing should not be underestimated. Micromechanically established theories have to be carefully validated by laboratory testing before applying them to problems involving real geomaterials. In this research, a comprehensive experimental investigation has been carried out in this study by means of HCA to revisit the anisotropic behaviour of geomaterials.

This paper offers a wide range of experimental data and evidence on soil behaviour under monotonic loading conditions taking into account the effects of the inherent and induced anisotropy, density and particle shape, stress history and combined influence of the rotation of principal axes as well as the intermediate principal stress. The experimental data on natural sand are particularly important for development and refinement of advanced constitutive models, while the tests on glass beads will have an impact on specific numerical simulations at the particlescale level based on the discrete element modelling (DEM). In addition to the phenomenological observations, a great attention has been placed on applying recently acquired micromechanical theories to understand the strength anisotropy and deformation non-coaxiality observed in real geomaterials.

\section{Apparatus and test procedures}

\subsection{Hollow cylinder apparatus}

In this study, the hollow cylinder apparatus, developed by GDS (Geotechnical Digital Systems) Instruments Ltd, was used. A schematic cross section of the GDS HCA is shown in Fig. 1. The cell contains the hollow cylindrical specimen with inner radius of $30 \mathrm{~mm}$, outer radius of $50 \mathrm{~mm}$ and

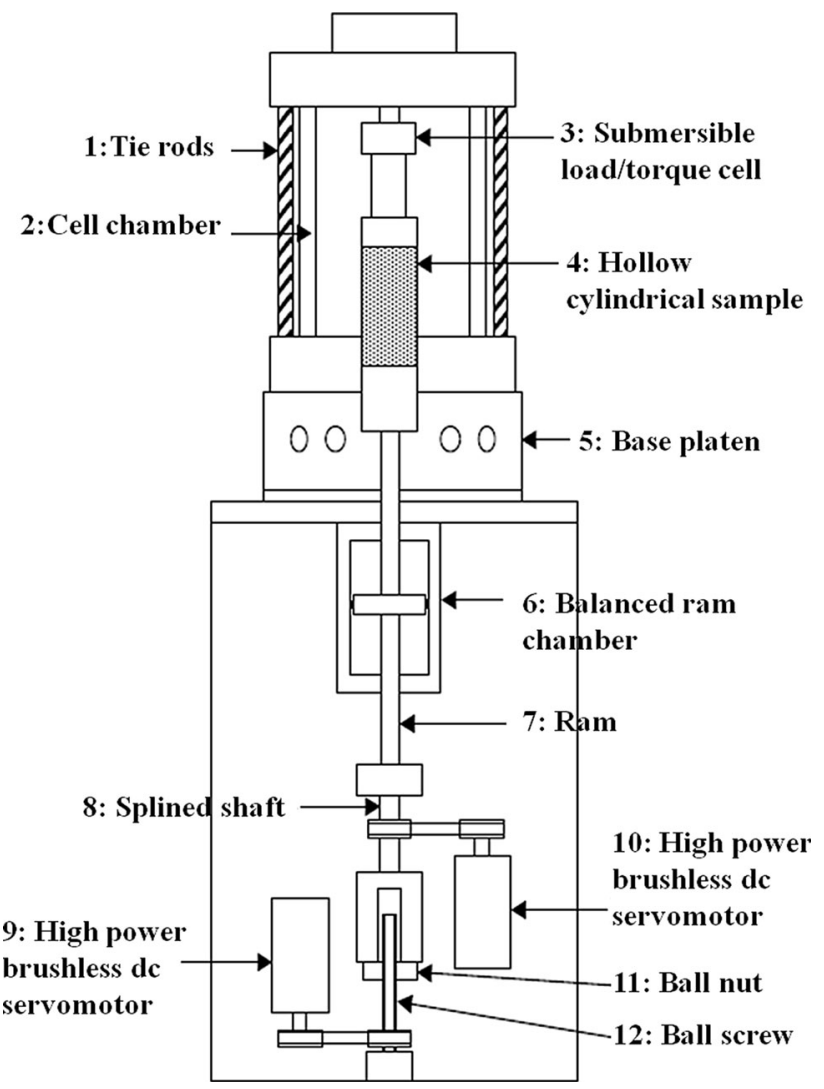

Fig. 1 Schematic cross section of the GDS hollow cylinder apparatus

height of $200 \mathrm{~mm}$. The specimen is subjected to axial load $W$, torque $M_{\mathrm{T}}$, inner cell pressure $p_{\mathrm{i}}$ and outer cell pressure $p_{\mathrm{o}}$. The axial load and displacement are generated and controlled by a high-power brush servomotor attached to the base of the ball screw. Rotation of the principal stress direction is achieved by means of second servomotor attached to the splined shaft, which generates torque or angular displacement as required. The outer pressure, the inner pressure and the back pressure are controlled and/or measured by three digital pressure/volume controllers (DPVC) of $2 \mathrm{MPa} / 200 \mathrm{cc}$ capacity. The axial load and the torque are monitored by a submersible load/torque cell attached rigidly to the cell top. The pore pressure is measured using an external pore pressure transducer connected to the base pedestal. The axial displacement and the rotation are measured by digital encoders mounted in the actuator unit.

In monotonic shear, the application of axial load $W$, torque $M_{\mathrm{T}}$, inner cell pressure $p_{\mathrm{i}}$ and outer cell pressure $p_{\mathrm{o}}$ enables the control of four stress components, axial stress $\sigma_{\mathrm{z}}$, radial stress $\sigma_{\mathrm{r}}$, circumferential stress $\sigma_{\theta}$ and shear stress $\sigma_{\theta z}$, on an element in the wall of the hollow cylindrical specimen. The radial strain $\varepsilon_{\mathrm{r}}$, circumferential strain $\varepsilon_{\theta}$ and shear strain $\gamma_{\theta z}$ were measured indirectly from the changes of inner and outer radii of the specimen. The 
radius changes were computed from the changes of the volume in the inner chamber and the specimen measured by the two DPVCs. The stresses and strains are calculated following the formulations of Hight et al. [24] as listed in Table 4 in 'Appendix'. The stress ratio $\eta$ used in this paper was defined as the ratio of deviatoric stress $q$ to effective mean stress $p^{\prime}$.

All the tests were controlled by the user's PC running GDSLAB software. For the monotonic loading tests performed in this study, two default control modules are available: (1) HCA stress path loading (this module controls the test by four parameters, $p, q, b$ and $\alpha$ ) and (2) HCA strain path loading (this module provides independent linear control of $p$, axial displacement, $b$ and $\alpha$, where $q$ is a passive variable dependent on the applied axial displacement). An option for a drained or undrained test is provided for both control modules. It needs to be noted that, in the HCA strain path loading mode, when $\alpha<45^{\circ}$, specimens were sheared in a compression mode, and when $\alpha>45^{\circ}$, specimens were sheared in an extension mode. However, with $\alpha=45^{\circ}$, specimen was neither compressed nor extended and the axial displacement was found to be in a vanishingly small amounts. Therefore, such a loading path was not included due to technical limitations of the testing system to perform such tests in the deformation-controlled mode.

HCA tests often suffer from the occurrence of stress nonuniformities across the wall of the hollow cylindrical sample as a consequence of specimen geometry, end restraints during the application of torque and different internal and external pressures. By a thorough review of numerous previous studies on the stress non-uniformities in hollow cylinder specimens, Rolo [55] concluded that the most severe cases of non-uniformities are confined to the space where the difference between $p_{\mathrm{o}}$ and $p_{\mathrm{i}}$ is large. In order to minimize the sample non-uniformity, the experimental program was designed in the limited range of the ratio between the outer and inner cell pressures $0.9 \leq p_{\mathrm{o}}$ $p_{\mathrm{i}} \leq 1.2$, as suggested by Hight et al. [24]. With regard to the sample geometry, Rolo [55] suggested that for a given diameter, increasing sample's wall thickness increases the level of non-uniformity. An aspect ratio of $H$ (height)/OD (outer diameter) $\geq 1.8$ was suggested to provide end restraint-free conditions. In the present study, this condition was well satisfied with aspect ratio of $H / O D=2.0$, and in this respect, the non-uniformity is considered less significant. HCA tests on granular soils are often carried out on specimens enclosed between outer and inner rubber membranes. Since thin rubber membranes have very low flexural stiffness, the membrane penetration (MP) is caused mainly by the intrusion of the membrane into the peripheral voids of a granular specimen. In order to make a confident assessment of actual volume changes and stress-strain behaviour of saturated granular materials in this study, the membrane penetration correction was determined in accordance with the theoretical equations for the unit membrane penetration proposed by Sivathayalan and Vaid [60].

\subsection{Tested materials and sample preparation}

Leighton Buzzard (Fraction B) sand and Ballotini glass beads were tested in this study. Leighton Buzzard sand is standard sand consisting mainly of sub-rounded quartz particles with some carbonate materials. The Ballotini glass beads are made of high-quality pure soda-lime glass. The index properties of the two materials are summarized in Table 1. Scanning electron micrographs of Leighton Buzzard sand and Ballotini glass beads are shown in Fig. 2a, b, respectively.

The water sedimentation method was used to prepare all the samples. This method mimics natural depositional environment satisfactorily and enables preparation of relatively homogeneous reconstituted sand samples with controlled density [70]. Denser specimens were compacted to a uniform relative density by tapping the sides of the outer mould. Water was supplied throughout this step to push out the air from the sand. To ensure high saturation of specimens, de-aired water was flushed throughout the specimen. The specimen was left overnight with a back pressure of $400 \mathrm{kPa}$ and outer and inner cell pressures of $420 \mathrm{kPa}$. The specimen was considered satisfactorily saturated when Skempton's B-value was greater than 0.96. The outer and inner cell pressures were then increased to $600 \mathrm{kPa}$ with the constant back pressure of $400 \mathrm{kPa}$. Hence, all the specimens were isotropically consolidated to the effective confining pressure $p^{\prime}=200 \mathrm{kPa}$.

\subsection{Experimental program}

Each series of drained monotonic shear tests with various loading directions carried out in this study is summarized in Table 2. The first two series of tests were performed on dense and medium dense Leighton Buzzard sand in order to generate a basic understanding of the anisotropic

Table 1 Physical properties of Leighton Buzzard sand and Ballotini glass beads

\begin{tabular}{lll}
\hline Property & $\begin{array}{l}\text { Leighton } \\
\text { Buzzard sand }\end{array}$ & $\begin{array}{l}\text { Ballotini } \\
\text { glass beads }\end{array}$ \\
\hline Mean grain size $D_{50}(\mathrm{~mm})$ & 0.62 & 1.35 \\
Effective grain size $D_{10}(\mathrm{~mm})$ & 0.45 & 1.15 \\
Uniformity coefficient $C_{\mathrm{u}}: D_{60} / D_{10}$ & 1.56 & 1.18 \\
Specific gravity $G_{\mathrm{s}}$ & 2.65 & 2.50 \\
Minimum void ratio $e_{\min }$ & 0.52 & 0.52 \\
Maximum void ratio $e_{\max }$ & 0.79 & 0.68 \\
\hline
\end{tabular}



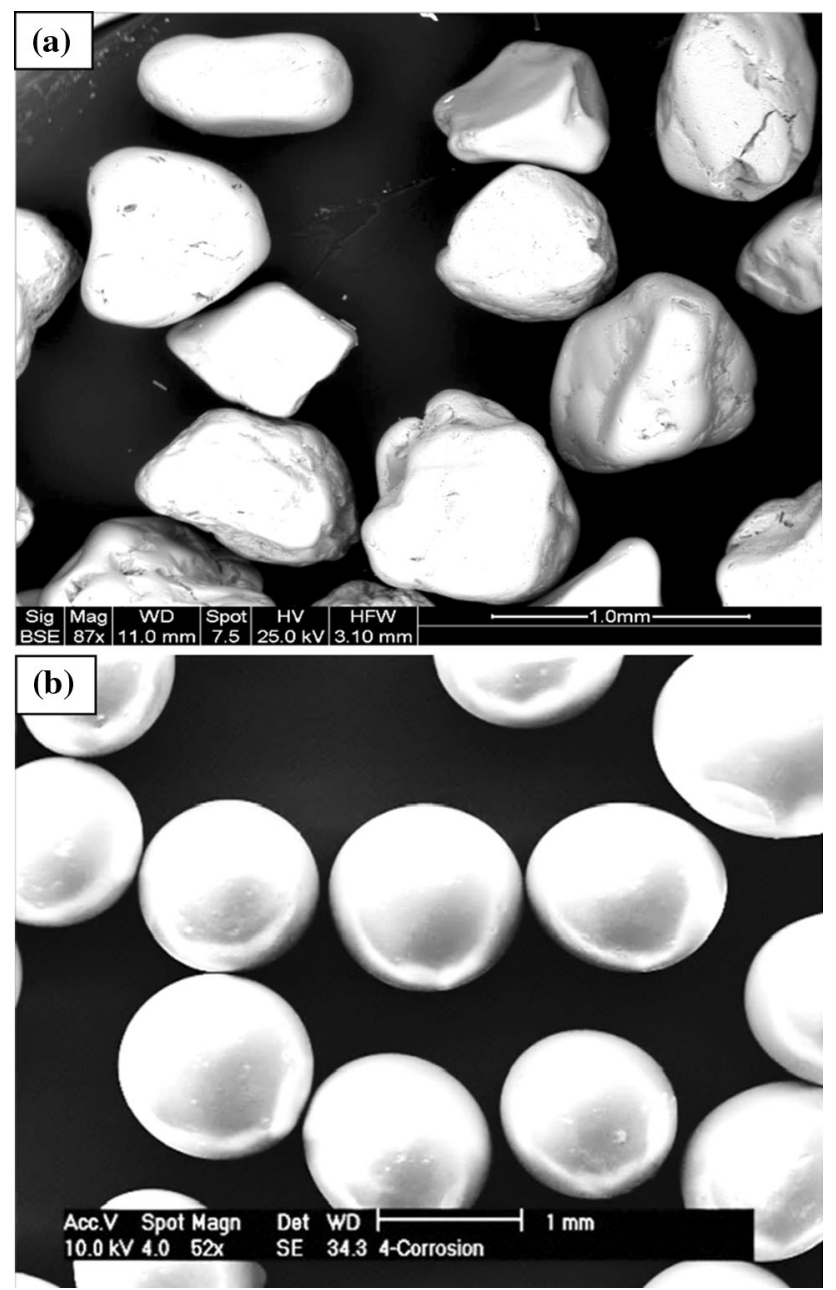

Fig. 2 Scanning electron micrograph of a Leighton Buzzard friction B sand and $\mathbf{b}$ Ballotini glass beads

behaviour of granular geomaterials. All the samples in Series 1 and 2 were sheared in a drained condition with various principal stress directions, as shown in Fig. 3. The results from these series of tests were used as a reference for comparison with the other series of tests. The third series of tests was performed on presheared sand specimens in order to investigate the impact of preshearing on the response of sand to subsequent loading. In this series of tests, a presheared specimen was obtained by shearing the isotropically consolidated specimen in the vertical direction (while maintaining $b=0.5$ and $p^{\prime}=200 \mathrm{kPa}$ ) up to the peak deviatoric stress $(\eta=1.2)$ and unloading it to a stress state with deviatoric stress $q=20 \mathrm{kPa}$ (see Fig. 4). It was observed that at the peak stress, the volumetric dilation of the specimen was less than $1 \%$ and the geometry of the specimen had no significant change based on visual inspection. Therefore, the specimen could be considered as uniform before reloading. The fourth series of tests was performed on dense sand with various combinations of $\alpha$ and $b$. The emphasis of this test series was placed on investigating the combined effects of principal stress direction and the intermediate principal stress. Finally, the fifth series of tests was performed on glass beads in order to study the effect of particle shape on the behaviour of granular materials. As shown in Table 2, each series of tests is labelled in such a way that the first two letters indicate the type of material and the third letter indicates material density followed by investigated testing parameters.

Figure 3 illustrates the stress paths for monotonic loading tests with different inclinations of the major principal stress $\left(\alpha=0^{\circ}, 15^{\circ}, 30^{\circ}, 60^{\circ}, 75^{\circ}\right.$ and $\left.90^{\circ}\right)$. During the tests, monotonic loading was applied in HCA strain path loading mode under drained conditions. To ensure full discharge of water from the specimen, the axial strain was increased at a slow rate of $0.05 \% / \mathrm{min}$. In all the tests, the value of the mean effective stress $p^{\prime}$ and the intermediate principal stress parameter $b$ was maintained constant. It needs to be noted that due to the limitations of the HCA, the value of $\alpha$ cannot be accurately controlled at very low levels of deviatoric stress. Therefore, in all the tests, a deviatoric stress of $15 \mathrm{kPa}$ was applied using HCA stress path loading mode before the rotation of the major principal stress direction was implemented. It should also be pointed out that since the calculations of stresses and

Table 2 Initial conditions for monotonic shear tests

\begin{tabular}{llllr}
\hline Test series & Test no. & $D_{\text {rc }}(\%)$ & $e_{\mathrm{c}}$ & $\alpha\left(^{\circ}\right)$ \\
\hline Series 1: Dense sand & LBD & 76 & 0.58 & $0,15,30,60,75,90$ \\
Series 2: Medium sand & LBM & 43 & 0.67 & 0.5 \\
Series 3: Presheared sand & LBD-PL & 76 & 0.58 & 0.5 \\
& & 73 (after preshearing) & & 0.5 \\
Series 4: Different $b$-values & LBD-B00 & 76 & 0.58 & 0 \\
& LBD-B02 & 76 & 0.58 & 0.2 \\
& LBD-B10 & 76 & 0.58 & 1.0 \\
Series 5: Ballotini glass beads & GBD & 90 & 0.54 & 0.5 \\
\hline
\end{tabular}

$D_{\mathrm{rc}}$ relative density after consolidation, $e_{\mathrm{c}}$ void ratio after consolidation, $\alpha$ principal stress direction, $b$ intermediate principal stress parameter 


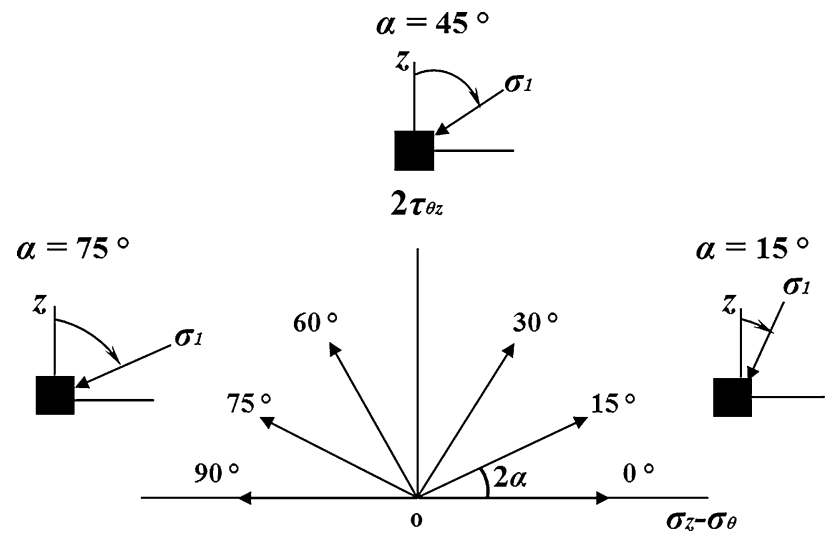

Fig. 3 Stress paths for monotonic loading tests

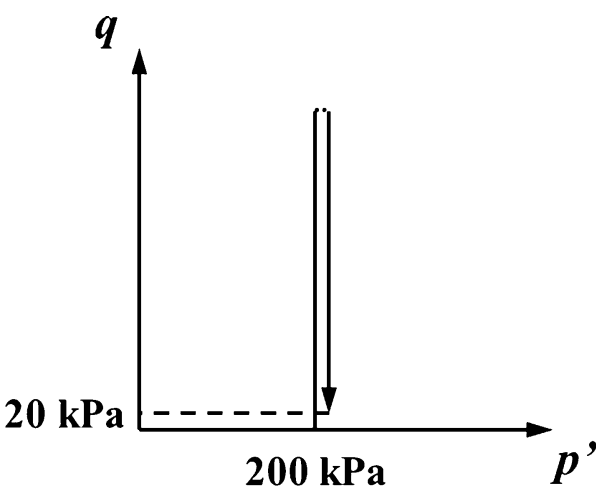

Fig. 4 Designed stress paths in $q-p^{\prime}$ stress space for preshearing tests

strains in HCA testing are based on global measuring system, the post-peak stress-strain curves could be subject to considerable error due to severe changes in sample thickness and curvature along the sample height. Nonetheless, the post-peak stress-strain behaviour remains very useful for qualitative assessment of soil behaviour and thus is included in all the plots.

\section{Results and discussions}

\subsection{Material anisotropy}

\subsubsection{Stress-strain behaviour}

The first series of tests, performed on dense Leighton Buzzard sand, is shown in Fig. 5a. The effect of anisotropy produced during sample preparation is apparent in both stress ratio and volumetric strain responses. For volumetric strain shown in the figures, a positive value along the vertical axis indicates contraction and the negative indicates dilation.

It can be observed from Fig. 5a that the shear strength reduces and the volumetric compressibility increases with

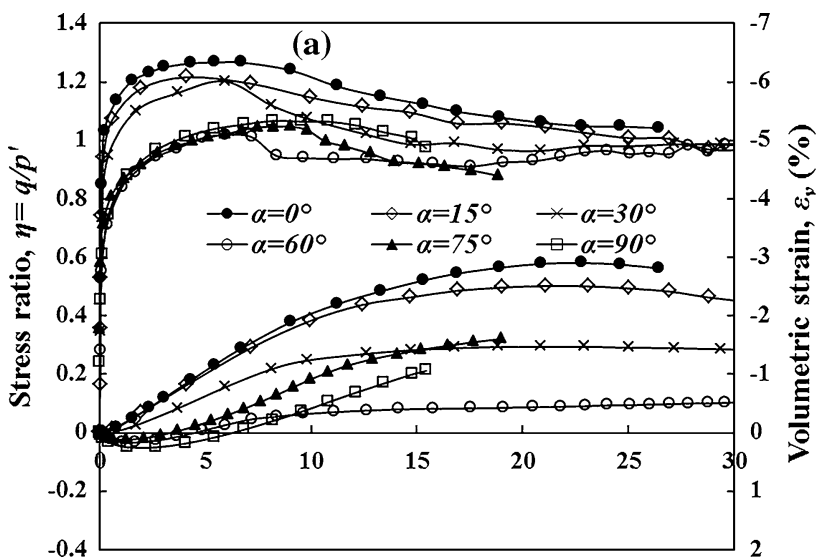

Deviatoric strain, $\varepsilon q(\%)$

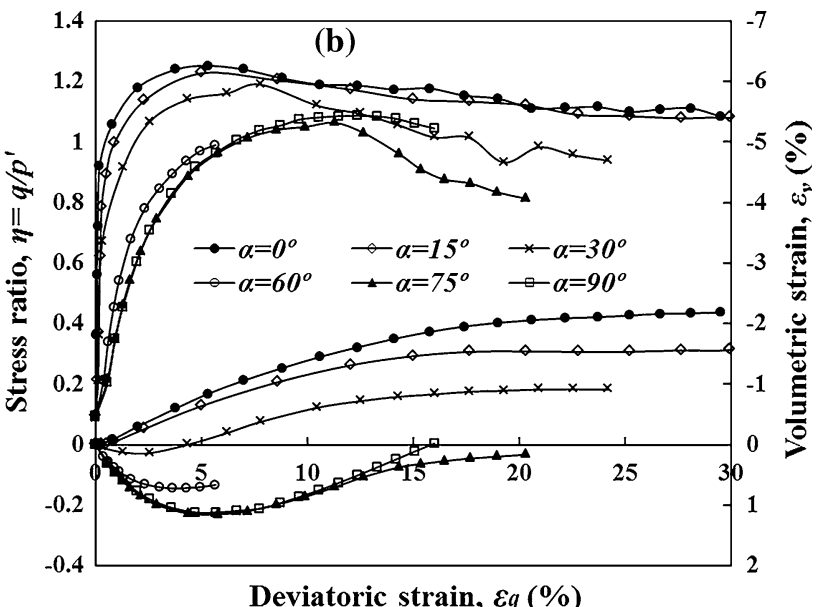

Fig. 5 Stress-strain behaviour at different loading directions for dense sand: a non-presheared; b presheared

increasing values of $\alpha$. The highest peak was obtained when the major principal stress direction was vertical, and it was reduced dramatically as the direction of the major principal stress was changed from $\alpha=30^{\circ}$ to $\alpha=60^{\circ}$. Similar observations have been reported by Arthur and Menzies [3] in cubical triaxial tests on tilted samples, Oda et al. [48] in plane strain tests, Arthur et al. [4] in directional shear cell tests, Cai et al. [9] and Yu et al. [75] in HCA tests.

The impact of preshearing on the material response to sub-sequential loading has been investigated by comparing test results on samples with and without preshearing histories as shown in Fig. 5a, b, respectively. Both figures demonstrate dependence of stress-strain behaviour on the direction of principal stress axes $\alpha$ for monotonic shear tests from test series LBD and LBD-PL, respectively.

It is clear that the preshearing history to the peak stress has a noticeable effect on the subsequent stress-strain response of sand. Larger initial contraction was observed at $\alpha=60^{\circ}, 75^{\circ}$ and $90^{\circ}$ for presheared specimens. The dependence of Young's secant modulus $E_{50}$ (evaluated 


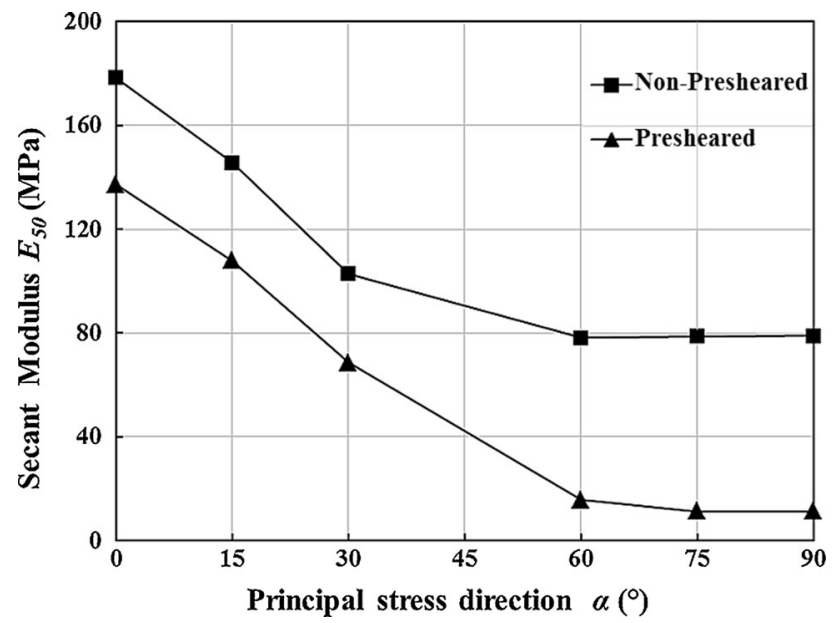

Fig. 6 Comparison of the secant modulus $E_{50}$ obtained at different loading directions between non-presheared sand and presheared sand

between $q=15 \mathrm{kPa}$ and $q=q_{\max } / 2$ ) on $\alpha$ for test with and without a preshearing is compared in Fig. 6. As shown in the figure, for both non-presheared and presheared specimens, the stiffest response is seen for loading in the vertical deposition direction when $\alpha=0^{\circ}$ and the strain response becomes softer with increasing values of $\alpha$. By comparing the two curves, a significant reduction in initial stiffness occurred when sand specimen experienced a preshearing history to peak stress and the reduction is especially large when $\alpha=60^{\circ}, 75^{\circ}$ and $90^{\circ}$.

Figures 5 and 6 demonstrate a noticeably softer response in stress-strain relationships, severer initial contraction and larger strains to reach the peak stress ratios for all the loading directions obtained for the presheared specimens. This observation is intriguing as it contradicts recent findings reported in the literature [e.g. 8, 13-17, 20]. It should be pointed out, however, that the effects of drained preshearing reported in the literature were investigated for loose granular materials under undrained conditions, whereas the current study was carried out on relatively dense sand under drained conditions. As a result, the changes in void ratios induced by preshearing in the current study were significantly smaller than those reported in the literature. As a matter of fact, it can be seen from Table 2 that the relative density of specimens reduced only by $3 \%$ during drained preshearing, which is not enough to explain the difference in the mechanical behaviours of the non-presheared and presheared specimens. Hence it can be hypothesized that the peak effective stress ratio, $\eta=1.2$, imposed during drained preshearing, alters the behaviour of subsequent loading via another role, more likely changing the soil fabric as a result of stress-induced anisotropy. This hypothesis is consistent with other research findings reported in the literature [e.g. 8, 13-17, 20].

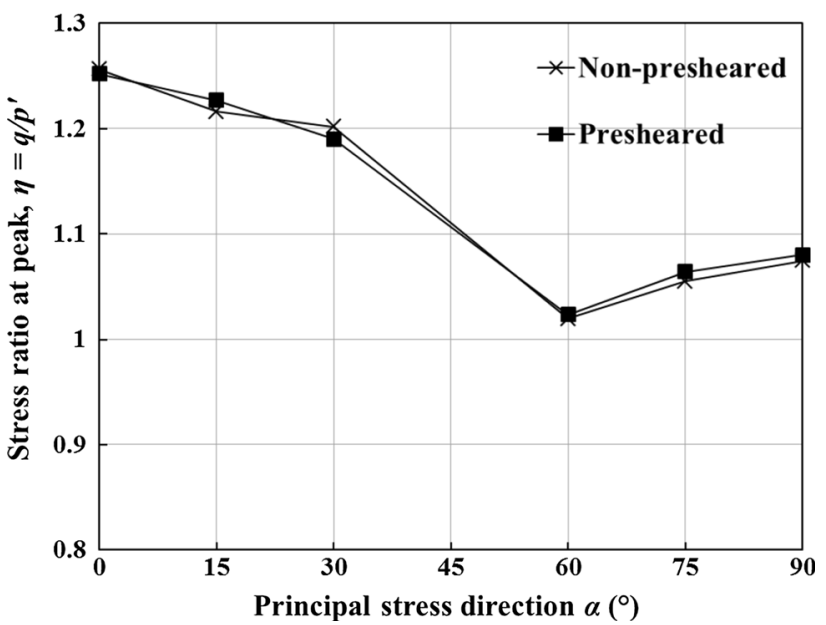

Fig. 7 Comparison of the peak stress ratio obtained at different loading directions between non-presheared sand and presheared sand

\subsubsection{Strength anisotropy}

Values of the peak stress ratio $\eta_{\mathrm{p}}$ at different major principal stress direction $\alpha$ obtained from test series LBD and LBD-PL are compared in Fig. 7. It can be seen from Fig. 7 that the variation of the peak stress ratios with principal stress direction shows similar trend patterns for the two series of tests. The highest peak stress ratio was obtained when the major principal stress direction was parallel to the deposition direction (i.e. $\alpha=0^{\circ}$ ), and the lowest value was obtained at $\alpha=60^{\circ}$. The specimen strength reverted slightly from $\alpha=60^{\circ}$ to $90^{\circ}$. Similar observations are reported by Miura et al. [41]. It is interesting to see that despite significant difference in the stress-strain response between the non-presheared and presheared specimens, the values of the peak stress ratio measured at different loading directions for the two specimens are almost the same.

Using 2D discrete element code PFC2D, Li and $\mathrm{Yu}$ [36] prepared and tested anisotropic specimens consisting of non-spherical particles under monotonic loading with different fixed strain increment directions. The particles were formed by clumping two equal-sized discs together with the distance between the disc centres equal to 1.5 times the disc radius. In their simulations, an initially anisotropic sample was prepared using a deposition method and a presheared sample was obtained by shearing the initially anisotropic specimen in the deposition direction to $25 \%$ axial strain and then unloading it to the isotropic stress state. The prefailure stress ratio (corresponding to $2 \%$ of axial strain) with different loading directions obtained from initially anisotropic samples and presheared samples was analysed thoroughly by $\mathrm{Li}$ and $\mathrm{Yu}$ [36]. Their DEM simulations and the HCA test results from the current study show a similar variation trend. The prefailure stress ratio continues decreasing when the loading direction rotated 
farther away from the vertical direction, and a slight increase in the specimen strength is observed when approaching loading in the horizontal direction $\left(a=90^{\circ}\right)$. However, $\mathrm{Li}$ and $\mathrm{Yu}$ [36] observed a clear strength reduction at each loading direction for the presheared samples, which is different from the HCA results. The reduction in the shear strength in $\mathrm{Li}$ and Yu's DEM simulations could be due to the significant increase in the void ratio of presheared samples (i.e. average increase of $11 \%$ from 0.20 to 0.22 ), which is much larger than that induced by preshearing to peak stress in the laboratory HCA tests (i.e. average increase of $2 \%$ from 0.58 to 0.59 ).

\subsubsection{Deformation non-coaxiality}

The numerical study carried out by $\mathrm{Li}$ and $\mathrm{Yu}$ [36] shows that a preloading history may have significant effects on the anisotropic behaviour of granular materials to subsequent loading. Similar results were observed in laboratory experiments done by several researchers $[58,59,71]$ with the fixed principal stress direction. However, laboratory investigation on the effect of preshearing on deformation non-coaxiality of real geomaterials remains limited.

The major directions of stress and strain increment obtained from test series LBD and LBD-PL are plotted against the stress ratio in Fig. 8a, b, respectively. During shearing, the direction of major principal stress $\alpha$ was fixed, as indicated by solid lines in the figures. The calculated strain increment directions are indicated by dashed lines with open circle symbols. The strain increments of $0.05 \%$ were used to calculate the major strain increment direction in all the tests. It needs to be noted that as elastic strain increment only takes a much smaller portion of the total strain increment compared to that of the plastic strain increment [21], the total strain increment instead of the plastic strain increment is used in the following analysis. The results obtained from test series LBD and LBD-PL supplement the observations made by $\mathrm{Li}$ and $\mathrm{Yu}$ [36]. The degree of non-coaxiality observed in the tests conducted on presheared specimens is significantly different from that obtained from non-presheared specimens. Figure $8 \mathrm{~b}$ shows that significant non-coincidence between the stress and strain increment directions was observed at $\alpha=15^{\circ}, 30^{\circ}$, $60^{\circ}$ and $75^{\circ}$. Similarly, in the 2D DEM simulations, it was found that the degree of non-coaxiality was greatly enlarged by the preshearing history to the prefailure stress ratio [36]. It needs to be noted that in $\mathrm{Li}$ and Yu's simulation [36], loading was applied in a strain-controlled mode with the principal strain direction fixed. However, by comparing the results between stress-controlled and straincontrolled monotonic loading tests, $\mathrm{Li}$ and $\mathrm{Yu}$ [36] pointed out that loading mode does not significantly affect measured degree of non-coaxiality.
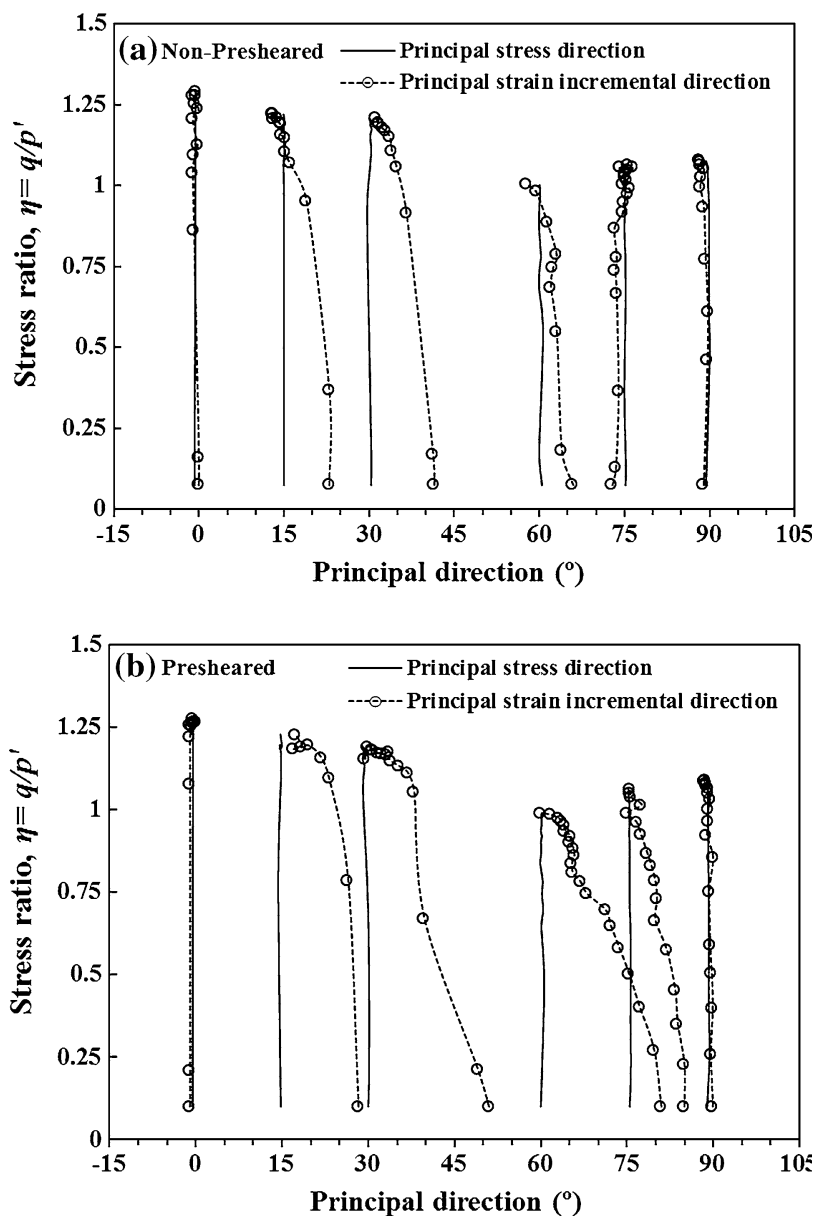

Fig. 8 Stress and strain increment directions at different loading directions for dense sand: a presheared sand; $\mathbf{b}$ non-presheared sand

\subsection{Micromechanical interpretation in aid of the SFF relationship}

\subsubsection{A brief summary of the stress-force-fabric relationship}

DEM simulations provide not only the continuum-scale observation on the stress-strain responses, but also the detailed particle-scale information to enable in-depth micromechanical investigations. It is now well recognized that granular materials may form different internal structures during deposition history, which may go through significant changes during shearing. Previous micromechanical investigations showed that the anisotropy in particle orientation is least sensitive to loading [35, 49]. However, during shearing, the contacts tend to concentrate in the loading direction. The anisotropy in the contact normal density has now been widely used as the fabric descriptor when studying the loading-induced anisotropy.

The stress-force-fabric relationship originally proposed by Rothenburg and Bathurst [56] offers analytical insight 
into the force-bearing capacity of granular materials. The tensorial form developed by $\mathrm{Li}$ and $\mathrm{Yu}$ [38] is more convenient in the study of strength anisotropy and deformation non-coaxiality. A brief summary is provided here for completeness. The microstructural definition of the stress tensor expresses the continuum-scale stress tensor $\sigma_{i j}$ as the tensor product of contact forces $f_{\mathrm{i}}^{\mathrm{c}}$ and contact vectors $v_{\mathrm{i}}^{\mathrm{c}}$ :

$\sigma_{i j}=\frac{1}{V} \sum_{\mathrm{c} \in V} v_{i}^{\mathrm{c}} f_{j}^{\mathrm{c}}$

in which $V$ stands for the volume of interest.

By examining the directional statistical features of contact vectors, contact forces and their statistical dependence, $\mathrm{Li}$ and $\mathrm{Yu}$ [37] demonstrated that the normalized deviatoric stress tensor $\eta_{i j}=\frac{\sigma_{i j}}{p}-\delta_{i j}$ can be expressed as:

$\eta_{i j}=\frac{1}{1+h}\left(G_{j i}^{\mathrm{f}}+C_{i j}^{\mathrm{v}}\right)$

where $h$ is the product of anisotropic tensors and often of limited magnitudes. This indicates the stress ratio and the principal stress direction are determined by the fabric anisotropic tensor $C_{i j}^{\mathrm{v}}$ and the force anisotropic tensor $G_{j i}^{\mathrm{f}}$. They proposed analytical expression for material strength and the degree of non-coaxiality in terms of the evolution of the fabric tensor $C_{i j}^{\mathrm{v}}$ characterizing structure anisotropy and the force tensor $G_{j i}^{\mathrm{f}}$ characterizing the anisotropy of particle interactions [37].

\subsubsection{Strength anisotropy}

Particle-scale information from DEM showed that when material approaches the peak stress ratio, the direction of the force anisotropy and fabric anisotropy is generally coaxial with loading direction. Therefore, the magnitude of peak stress ratio is determined by the magnitudes of force anisotropy and fabric anisotropy. It has been shown that as the loading directions change from $\alpha=0^{\circ}$ to $60^{\circ}$, the force anisotropy and fabric anisotropy decrease, leading to decreasing value of stress ratio. Upon further increase of $\alpha$ to $90^{\circ}$, the fabric anisotropy decreases continuously, while the force anisotropy increases, resulting in a slight increase in the stress ratio. This explains the variation of the peak strength over loading directions observed in DEM studies, which is also in qualitative agreement with the experimental data.

\subsubsection{Deformation non-coaxiality}

Based on the SFF relationship, $\mathrm{Li}$ and $\mathrm{Yu}$ [38] reported that non-coaxiality was quantitatively dependent on the relative direction, as well as the relative magnitude of the fabric
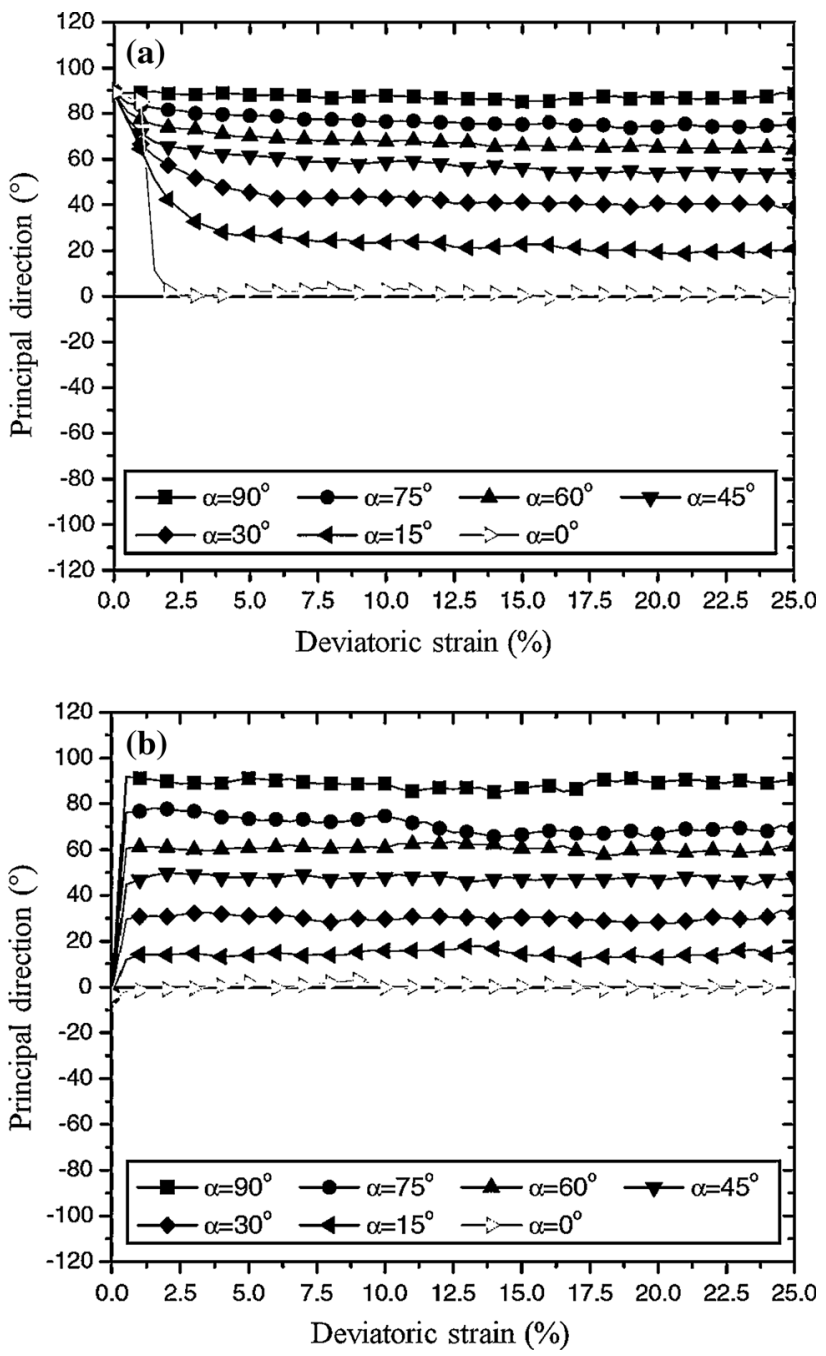

Fig. 9 Principal directions of: a fabric anisotropy and $\mathbf{b}$ contact force anisotropy during monotonic shear in the initially anisotropic sample [after 36]

anisotropy (Fig. 9a) and the contact force anisotropy (Fig. 9b). As the direction of force anisotropy is almost coaxial with the loading direction during shearing, noncoaxiality is the result of the principal directions of fabric anisotropy deviating from the loading direction. Microscopically, it was found that for simulation with loading direction parallel to the deposition direction $\left(\alpha=90^{\circ}\right)$, the principal direction of fabric anisotropy was coincident with loading direction throughout the shearing. In the test with loading direction perpendicular to the preloading direction $\left(\alpha=0^{\circ}\right)$, the principal directions of fabric anisotropy quickly approached to the loading direction at the initial stage of shearing. Hence, the material behaves almost coaxially when the samples are loaded in the direction of major principal stress parallel or perpendicular to the 
deposition direction. However, for simulations with loading direction fixed at $\alpha=75^{\circ}, 60^{\circ}, 45^{\circ}, 30^{\circ}$ and $15^{\circ}$, shown in Fig. 9a, the principal directions of fabric anisotropy gradually rotated in such a manner that they finally point in the loading direction at large strain levels Thus, it can be observed that the non-coaxiality degree decreases with increasing stress ratio and the granular material is nearly coaxial close to failure. As for the presheared specimens, the magnitude of fabric anisotropy was found to be larger than the initially anisotropic sample prepared by deposition. Accordingly, more significant deformation noncoaxiality was observed. Therefore, DEM simulations reported by $\mathrm{Li}$ and $\mathrm{Yu}$ [38] give a plausible explanation for the observations on Leighton Buzzard sand, shown in Fig. 8.

\subsection{Effects of material density and particle shape}

It is well known that void ratio is one of the most important parameters controlling the mechanical response of soils. The investigation of the effects of material density on the anisotropic behaviour of granular materials was carried out by comparing test results on dense sand (LBD) and medium dense sand (LBM). Glass beads have long been used to study anisotropic behaviour of 'idealized' granular materials [e.g. 23, 28, 29]. Their relatively simple geometry and uniform particle size distribution allowed the influence of particle shape to be examined independently. On the other hand, the application of glass beads in laboratory test provides comparable data for numerical as well as constitutive modelling of granular materials. Therefore, experiments on glass beads (GBD) were also performed in this study, and the results were compared with those of sand (LBD).

Figure 10 presents the comparison of the stress-strain curves obtained for dense sand and medium dense sand at

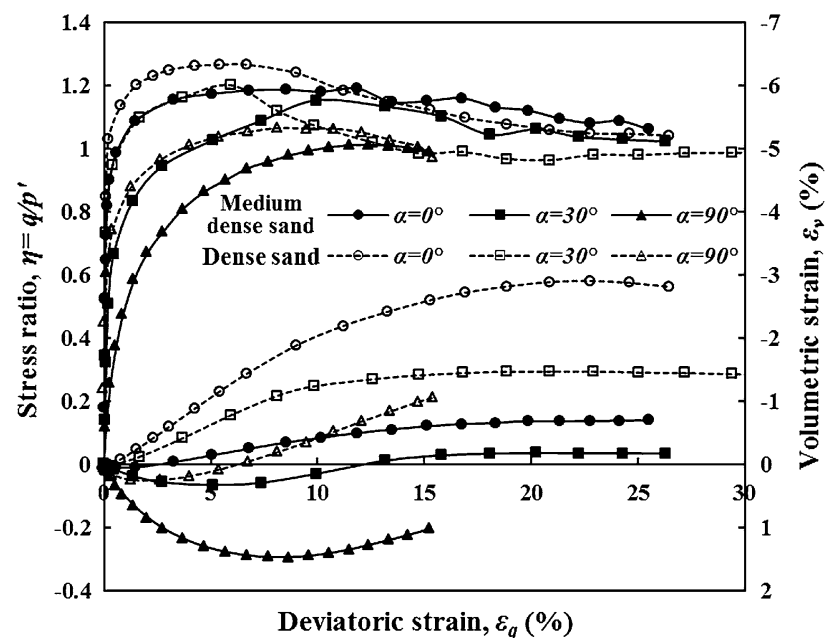

Fig. 10 Comparison of the stress-strain curves obtained at different loading directions between dense sand and medium dense sand

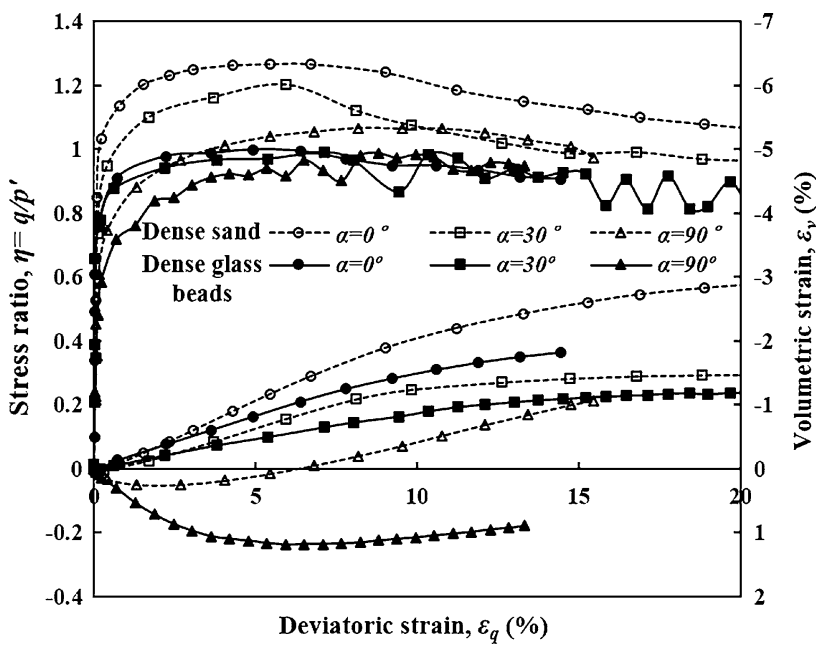

Fig. 11 Comparison of the stress-strain curves obtained at different loading directions between dense sand and dense glass beads

three representative loading directions $\left(\alpha=0^{\circ}, 30^{\circ}\right.$ and $90^{\circ}$ ). For a comparison purpose, the results from medium dense sand are plotted as solid lines, while the corresponding results of dense sand are shown as dashed lines. It can be observed from Fig. 10 that regardless of the loading direction, the medium dense sand tends to exhibit lower shear strength and more contractive volumetric strain than those of the dense sand. Moreover, larger deviatoric strain was required for the medium dense sand to reach the peak state.

The comparison of the results obtained from dense sand and glass beads is shown in Fig. 11 with solid lines representing glass beads and dashed lines representing dense sand. It can be seen from Fig. 11 that the glass beads tend to have lower shear strength and larger volume compressibility, even though the beads have higher relative density than that of the sand (glass beads: $90 \%$; dense sand: $76 \%$ ). It is also obvious from Fig. 11 that spherical glass beads exhibit more severe fluctuations in its stressstrain curves than angular sand [also known as stick-slip phenomenon, 18]. As indicated by Oda and Iwashita [45], there are two forms of inherent anisotropy from the microfabric point of view: (a) by preferred orientation of non-spherical particles and (b) by preferred orientation of unit vectors normal to contact surfaces. Therefore, the anisotropic stress-strain response observed in case of spherical glass beads was mainly caused by the anisotropic distribution of contact normally formed during deposition process.

A comparison of the peak stress ratios obtained at different loading directions from test series LBD, LBM and GBD is shown in Fig. 12. It can be observed that the general trend of the variation of peak stress ratios with increasing values of $\alpha$ is similar for the three series of tests. However, the results obtained from the tests on dense sand and medium dense sand show that the maximum difference 


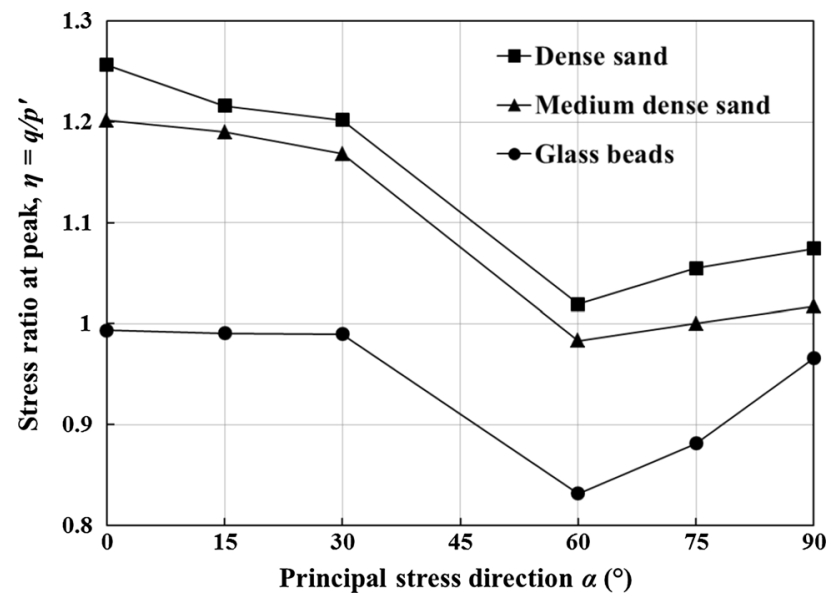

Fig. 12 Comparison of the peak stress ratio obtained at different loading directions between dense sand, medium dense sand and glass beads

between the peak stress ratios obtained from both series is only 0.06 and it was obtained at $\alpha=0^{\circ}$, even though the difference between the relative densities of the two samples is about $33 \%$. The difference between results obtained from dense sand and glass beads was more significant. As shown in Fig. 12, a large reduction in the material strength was observed when the angular sand was changed to the spherical glass beads even though the relative density of the glass beads was $14 \%$ higher than the dense sand.

Figure 13 shows the comparison of the calculated strain increment directions obtained at different loading directions from test series LBD, LBM and GBD. It can be seen that the magnitudes of the directions of strain increments were very similar at each loading direction for dense sand and medium dense sand. Therefore, the experimental results suggest that the effect of relative density on the noncoaxial behaviour of sand in monotonic shear is not significant. As indicated in Fig. 13, despite the slightly smaller degree of non-coaxiality in glass beads, the margin by which the non-coaxiality of dense sand exceeded that of the glass beads was limited to $3^{\circ}$. Hence, the effect of particle shape on the non-coaxial behaviour of sand in monotonic shear is also not significant.

\subsection{Effects of principal stress direction and intermediate principal stress}

As the most of field problems in geotechnical engineering are three dimensional, a soil is more likely to be subjected to an anisotropic stress state $\left(\sigma_{1} \neq \sigma_{2} \neq \sigma_{3}\right)$, together with a rotation of the principal axes. Experimental investigation on the effects of intermediate principal stress on soil behaviour has been an interesting topic in the last couple of decades [e.g. 27, 30, 44, 54, 57]. However, to the

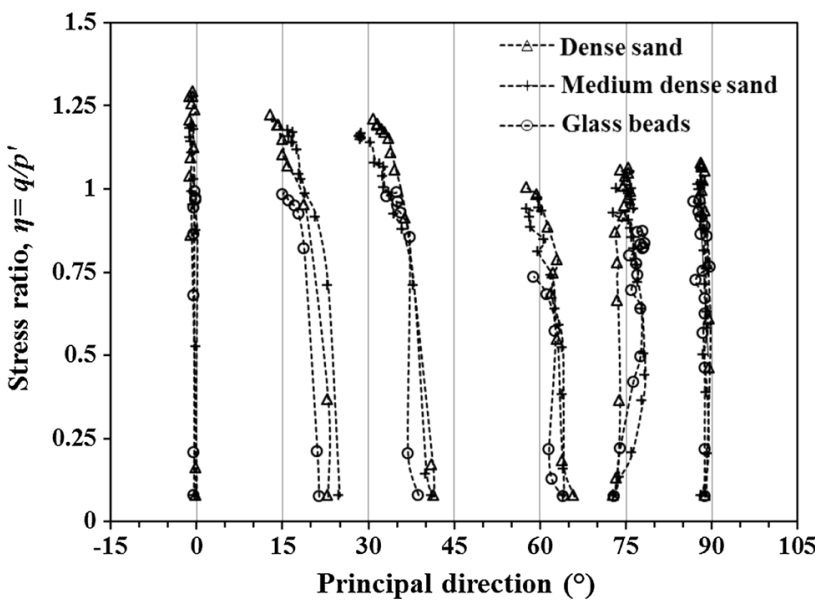

Fig. 13 Comparison of the strain increment directions obtained at different loading directions between dense sand, medium dense sand and glass beads

authors' knowledge, there is very limited data obtained from drained HCA test with various combinations of principal stress direction $\alpha$ and intermediate principal stress parameter $b$. Therefore, the combined effects of $\alpha$ and $b$ on the behaviour of granular materials under drained monotonic shearing were investigated in the present study.

\subsubsection{Stress-strain behaviour}

The stress-strain behaviour at different major principal stress directions for test series LBD-B00, LBD-B02, LBD and LBD-B10 are presented in Fig. 14. In general, irrespective of loading directions, the highest peak stress ratio was obtained when $b=0$ and a significant decrease in material strength was observed with increasing values of $b$. The volumetric response also shows a consistent pattern. The volumetric compressibility of the specimens increases with increasing $b$-value.

For the tests with the major principal stress direction $\alpha=0^{\circ}, 15^{\circ}$ and $30^{\circ}$, shown in Fig. 14a-c, at different loading directions the curves also show a clear decreasing strength from $b=0$ to $b=1$. For test with $b=1.0$, specimens failed quickly with a sharp drop in the stressstrain curve after the peak was reached. Comparing the volume change, all the samples tested at $\alpha=0^{\circ}, 15^{\circ}$ and $30^{\circ}$ show predominantly dilatant response. For tests with $b=0,0.2$ and 0.5 , there is no tendency for contraction. The specimens were dilating throughout the tests, as shown in Figs. 14a-c. However, for tests with $b=1.0$, volumetric response became dilatant after the initial contraction and with further shearing, associated with strain softening. It can be seen from Fig. 14d-f that typical trend indicated in the tests with $\alpha=0^{\circ}, 15^{\circ}$ and $30^{\circ}$ can also be observed in the tests with $\alpha=60^{\circ}, 75^{\circ}$ and $90^{\circ}$, that is, the shear 

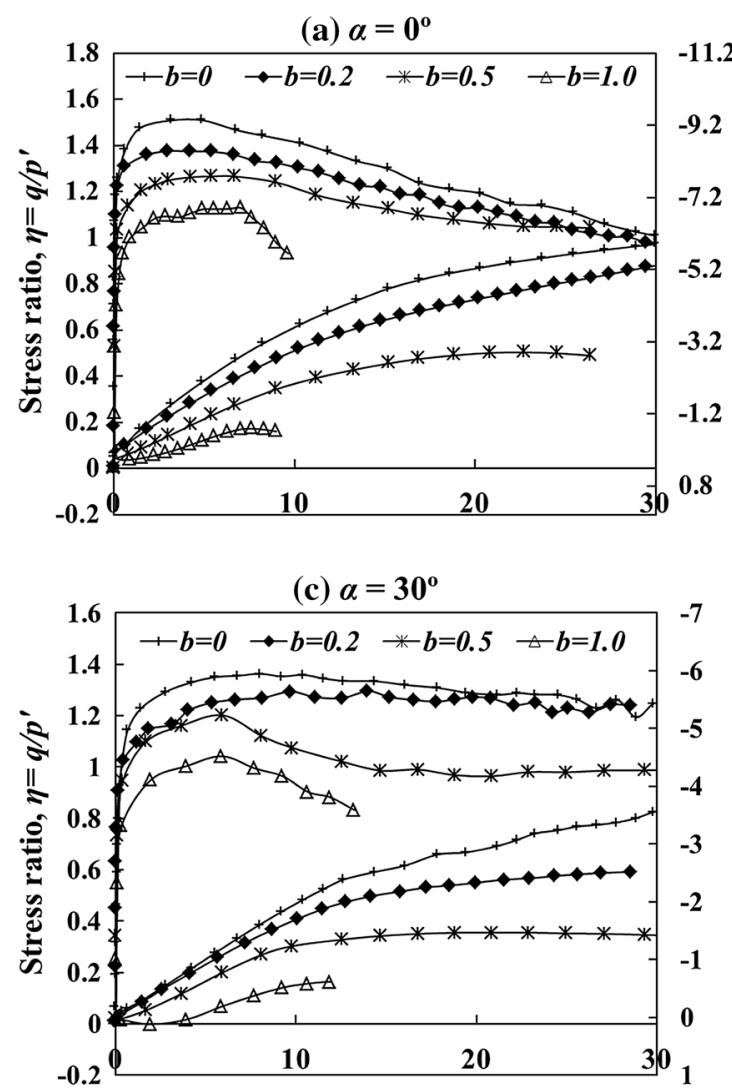

(e) $\alpha=75^{\circ}$

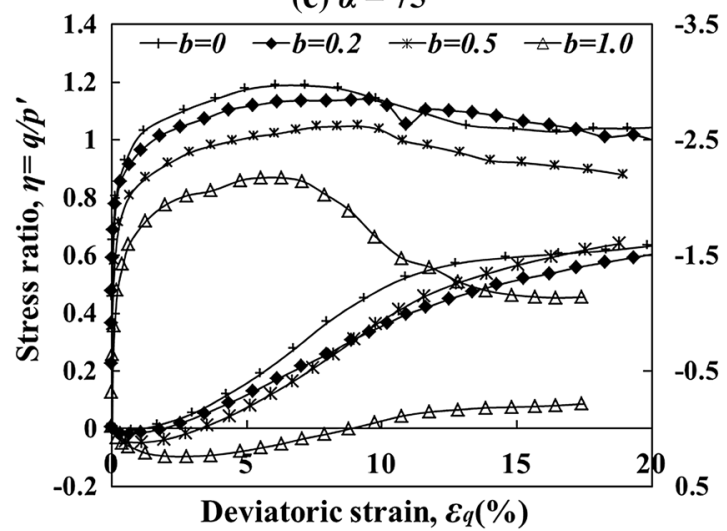

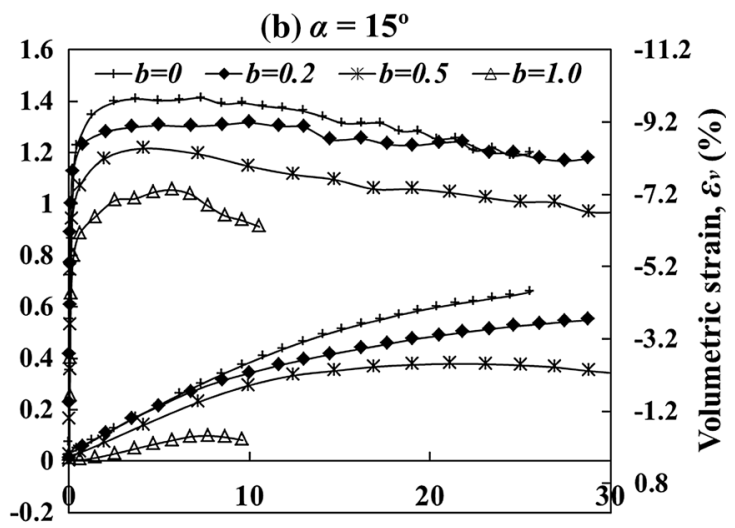

(d) $\alpha=60^{\circ}$
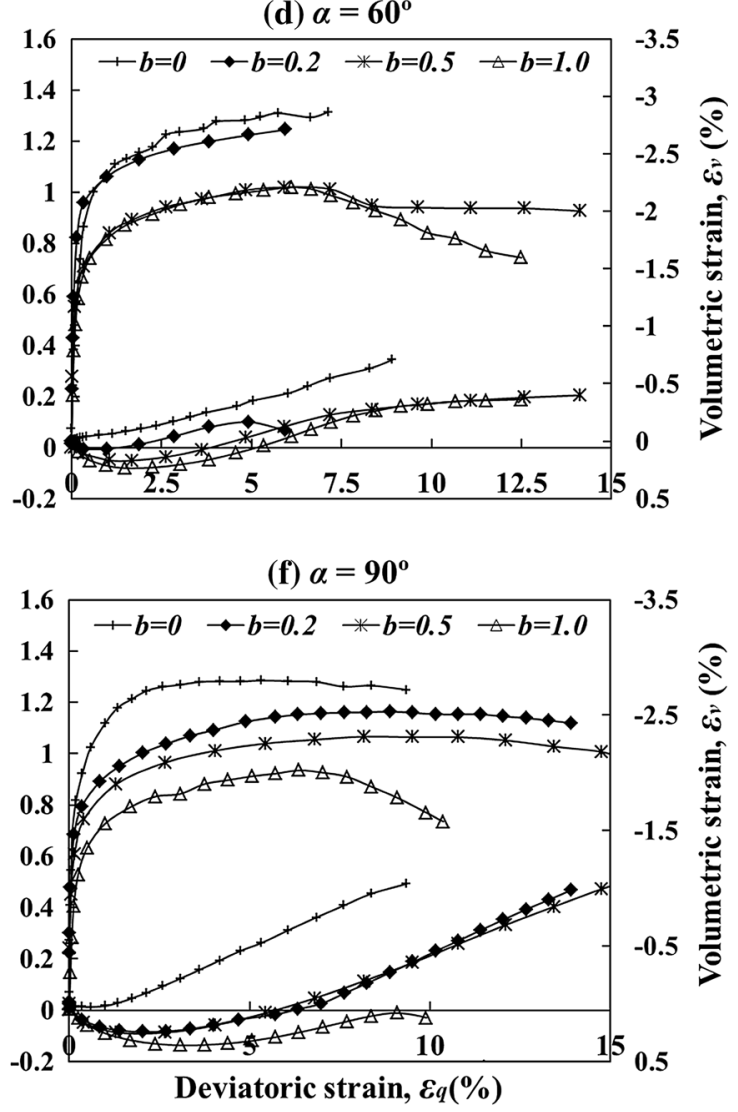

Fig. 14 Stress-strain behaviour at: $\mathbf{a} \alpha=0^{\circ} ; \mathbf{b} \alpha=15^{\circ} ; \mathbf{c} \alpha=30^{\circ} ; \mathbf{d} \alpha=60^{\circ} ; \mathbf{e} \alpha=75^{\circ} ; \mathbf{f} \alpha=90^{\circ}$ for tests with $b=0,0.2,0.5$ and 1.0

strength of sand reduces and the volumetric compressibility increases with increasing values of $b$. It is interesting to see that unlike in the tests with $\alpha=0^{\circ}, 15^{\circ}$ and $30^{\circ}$, apparent tendency for initial contraction was observed for all the tests with $\alpha=60^{\circ}, 75^{\circ}$ and $90^{\circ}$.

\subsubsection{Strength anisotropy and deformation non-coaxiality}

Different peak stress ratios measured at different principal stress directions for tests with different $b$-values are plotted in Fig. 15a. It can be seen that for the same loading direction, the value of the peak stress ratio reduced with increasing b-value. As the major principal stress direction deviates from the vertical, the peak stress ratios obtained at different $b$-values followed similar trend. That is, the stress ratio continued decreasing when the loading direction rotated further towards the vertical direction and a slight recovery of the specimen strength is observed at $\alpha=90^{\circ}$. As shown in Fig. 15b, the variation trend of the peak friction angle measured at different principal stress directions for test with different $b$-values is similar. As $b$-value changed from 0 to 0.5 , the strength increases and there is a 

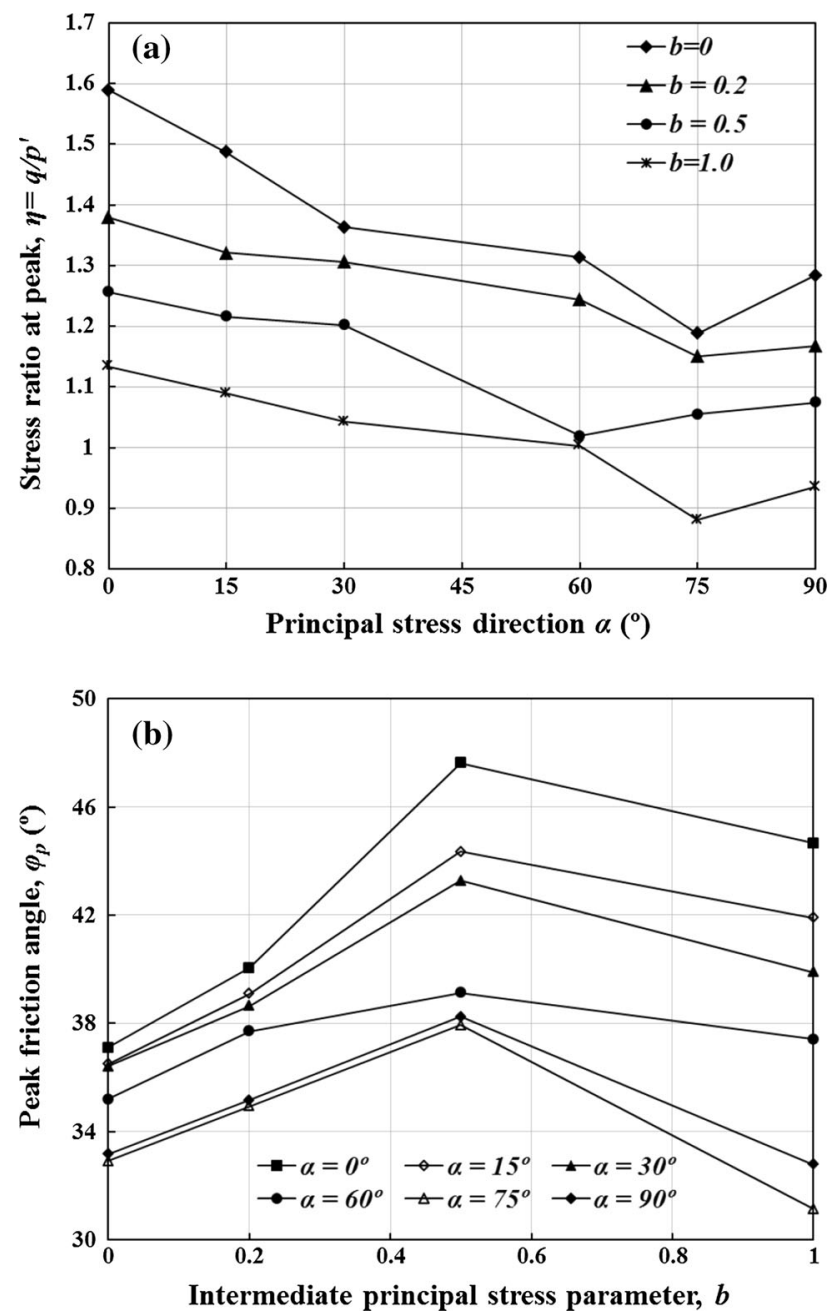

Fig. 15 a Peak stress ratio versus major principal stress direction for test with different $b$-values; b peak friction angle versus $b$-value for test at different major principal stress direction

drop in strength as $b$ further increases from 0.5 to 1.0. However, as indicated in the figure, the peak friction angles obtained at $b=1.0$ gradually shifted down with the increasing value of $\alpha$. For $\alpha=0^{\circ}, 15^{\circ}, 30^{\circ}$ and $60^{\circ}$, the lowest strength is reached at $b=0$, whereas for $\alpha=75^{\circ}$ and $90^{\circ}$, it is obtained at $b=1.0$. Above observations clearly show that both the inherent anisotropy and the intermediate principal stress may have a profound influence on the behaviour of sand with anisotropic fabric. Neglecting the effects of the soil anisotropy in the investigation of intermediate principal stress may result in inadequate interpretation of test results.

The principal strain increments calculated from test series LBD-B00, LBD-B02, LBD and LBD-B10 at $\alpha=15^{\circ}, 30^{\circ}, 60^{\circ}$ and $75^{\circ}$ are compared in Fig. 16. It can be seen that there is noticeable influence of the $b$-value on the non-coaxiality of sand. In general, at $\alpha=15^{\circ}, 30^{\circ}$ and $60^{\circ}$, the lower the $b$-value, the higher the degree of non-

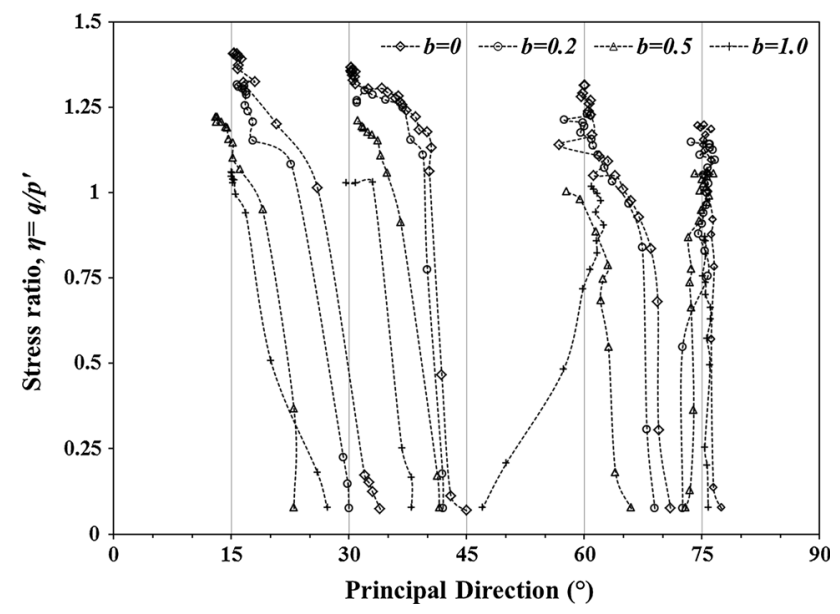

Fig. 16 Comparison of strain increment directions for tests with $b=0,0.2,0.5$ and 1.0 at: $\alpha=15^{\circ}, 30^{\circ}, 60^{\circ}$ and $75^{\circ}$

coaxiality. Tests with $b=0$ show a comparatively larger deviations between the major directions of stress and strain increment than other three test series. The largest deviations between the two directions occurred in the test with $b=0$ at $\alpha=15^{\circ}$, reaching about $20^{\circ}$. However, at $\alpha=75^{\circ}$, all the specimens behave almost coaxially throughout the tests.

Numerical studies based on 3D DEM have also evolved to investigate the effects of intermediate principal stress on the behaviour of initially isotropic granular materials [e.g. $5,65,66]$. However, the effect of inherent anisotropy was not considered in these simulations. The combined effects of loading direction and intermediate principal stress on the behaviour of granular materials in generalized three-dimensional stress state remain unaddressed. Hence, the fundamental relationship between the macro- and microscale responses of granular materials under generalized stress conditions is not well understood.

\subsection{Shear banding}

After each test, the specimen was held under vacuum in order to record any shear bands that had developed during shearing. Figure 17 presents different shear band patterns and inclination angles at different loading directions obtained from test series LBD. As shown in the figure, the angle of shear band inclination is measured from the vertical direction (centre line on the front surface of the specimen) to the direction of shear band plane on the front of the specimen.

It can be seen from Fig. 17 that bulging was observed for specimens tested with $\alpha=0^{\circ}, 15^{\circ}$ and $30^{\circ}$, and necking was observed for specimens tested with $\alpha=60^{\circ}, 75^{\circ}$ and $90^{\circ}$. Crossed shear bands were produced at $\alpha=0^{\circ}$ and $90^{\circ}$, and the intersections of the shear bands were mainly 


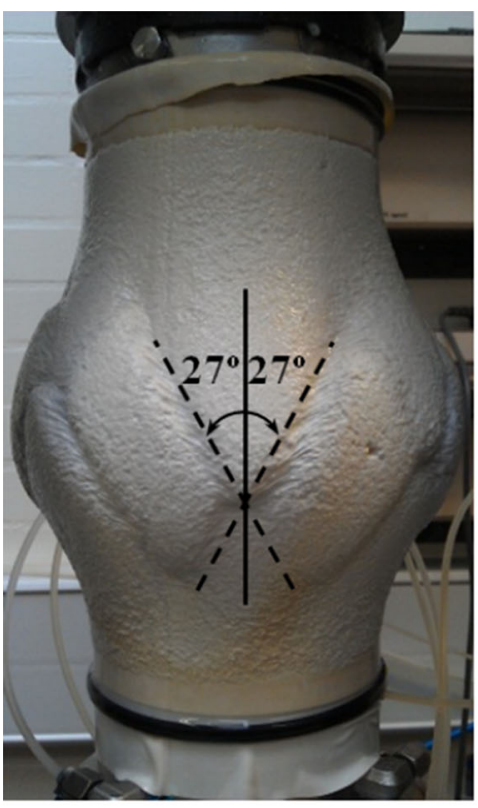

$\alpha=0^{\circ}$

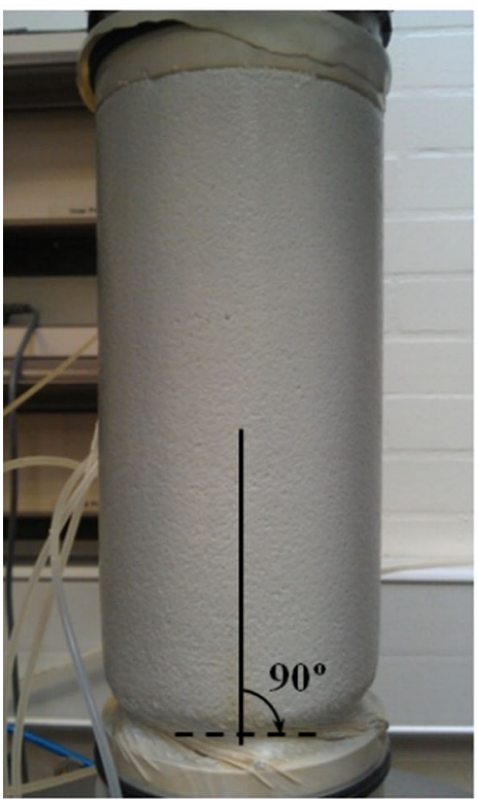

$\alpha=60^{\circ}$

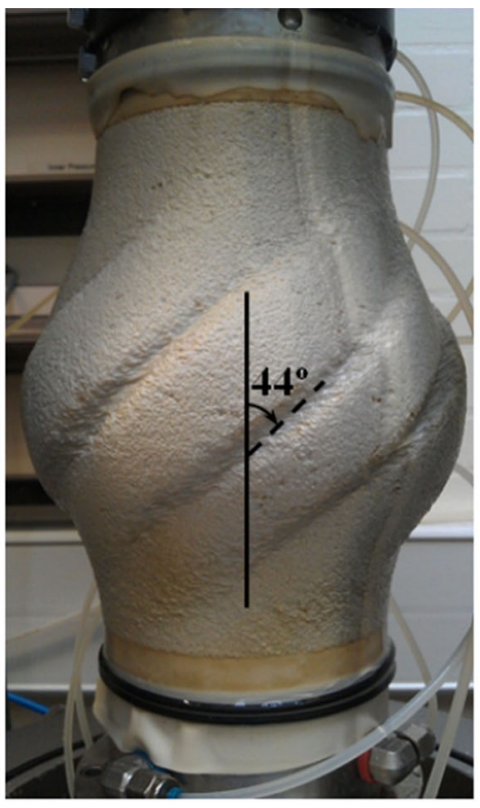

$\alpha=15^{\circ}$

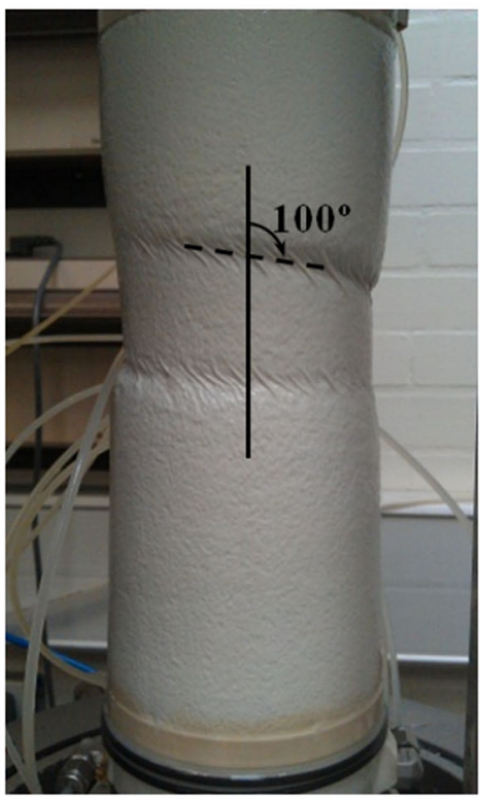

$\alpha=7^{\circ}$

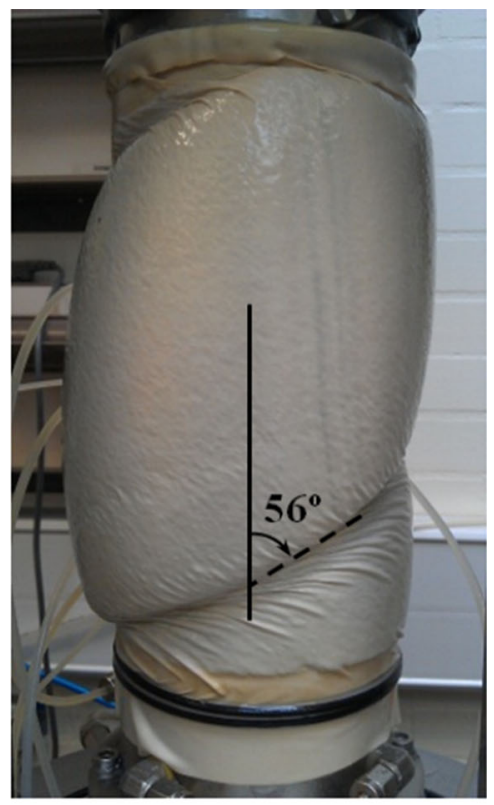

$\alpha=30^{\circ}$

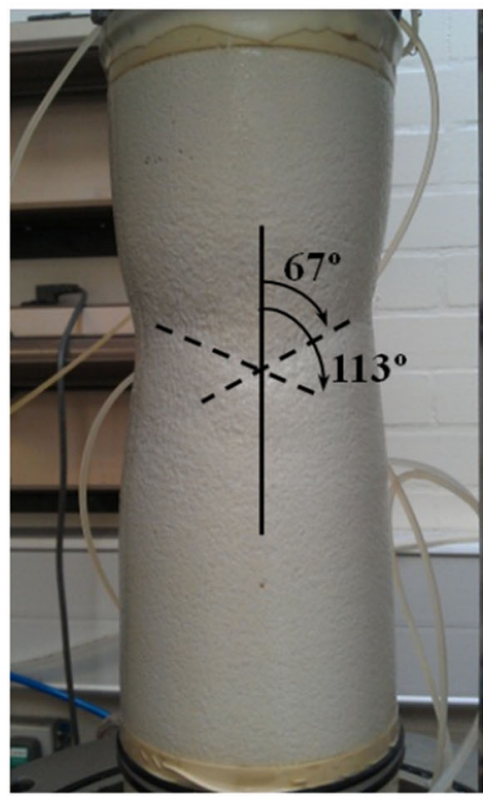

$\alpha=90^{\circ}$

Fig. 17 Shear bands developed in dense sand specimens at different loading directions

concentrated in the middle part of the specimen. For $\alpha=15^{\circ}$, several parallel spiral shear bands were wrapped around the body of the specimen with almost equal distance between each other. For $\alpha=30$ and $75^{\circ}$, single spiral shear bands were developed. However, for $\alpha=60^{\circ}$, specimen was twisted at the interface between the base pedestal and the specimen ends.

Based on force equilibrium, Coulomb's theory [11] states that failure occurs at the point of maximum obliquity, and the inclination of shear bands therefore coincides with the inclination of planes on which the ratio of shear to normal stress reaches its maximum value (mobilized plane). In this case, the angle $\theta_{\sigma}$ between the shear band orientation and the direction of major principal strain increment can be expressed as:

$\theta_{\sigma}=45^{\circ} \pm \varphi / 2$

where $\varphi$ is the friction angle.

By taking the magnitude of effective major and minor principal stresses at the peak stress state, the value of $\varphi$ at 
Table 3 Comparison of experimental shear band inclinations with theoretical predictions

\begin{tabular}{lllllll}
\hline$\alpha\left({ }^{\circ}\right)$ & 0 & 15 & 30 & 60 & 75 & 90 \\
\hline$\alpha_{\mathrm{sb}}\left({ }^{\circ}\right)$ & $-27,27$ crossed & 44 parallel & 56 single & 90 single & 100 single & 67,113 crossed \\
$\theta_{\sigma}\left({ }^{\circ}\right)$ & -21 (I) & -8 (I) & -7 (I) & 33 (I) & 49 (I) & 64 (I) \\
& 21 (II) & 38 (II) & 53 (II) & 87 (II) & 101 (II) & 116 (II) \\
\hline
\end{tabular}

$\alpha_{\mathrm{sb}}$ actual shear band inclinations measured in the experiments, $\theta_{\sigma}$ theoretical predicted shear band inclinations

different loading directions was calculated and the value of the angle $\theta_{\sigma}$ could therefore be obtained. The actual shear band inclinations obtained in the experiments $\left(\alpha_{\mathrm{sb}}\right)$ are compared with the theoretical predictions $\left(\theta_{\sigma}\right)$ in Table 3 . For the sake of comparison, the experimental shear band inclinations $\alpha_{\mathrm{sb}}$ and theoretical predictions $\theta_{\sigma}$ (mobilized plane I and II) are sketched in Fig. 18. It can be seen that at $\alpha=0^{\circ}$ and $90^{\circ}$ crossed shear bands were developed asymmetrically about the vertical direction, and they matched well with the two mobilized planes predicted by Coulomb's theory. However, in the tests with $\alpha=15^{\circ}, 30^{\circ}$, $60^{\circ}$ and $75^{\circ}$, the shear bands were developed in just one direction, which is inconsistent with theoretical predictions. From the microscopic point of view, Miura et al. [41] pointed that the interlocking between elongated sand particles with their long axes laid horizontally has the weakest resistance to shear stress on the bedding plane. Consequently, the specimen deforms most easily when the mobilized plane coincides with the bedding plane. By taking this anisotropic behaviour into consideration, it can be seen from Fig. 18 that for $\alpha=15^{\circ}, 30^{\circ}, 60^{\circ}$ and $75^{\circ}$ mobilized plane II is closer to the bedding plane than mobilized plane I. This means that the lowest shear resistance and largest sliding displacement will occur more likely on mobilized plane II rather than on mobilized plane I. The inclinations of shear bands measured in this study at different loading directions confirm Miura's theory.

\section{Conclusions}

This paper presents an experimental investigation revisiting anisotropic stress-strain-strength behaviour of geomaterials in drained monotonic shear using hollow cylinder apparatus. The test programme has been designed to cover the effect of material anisotropy, preshearing, material
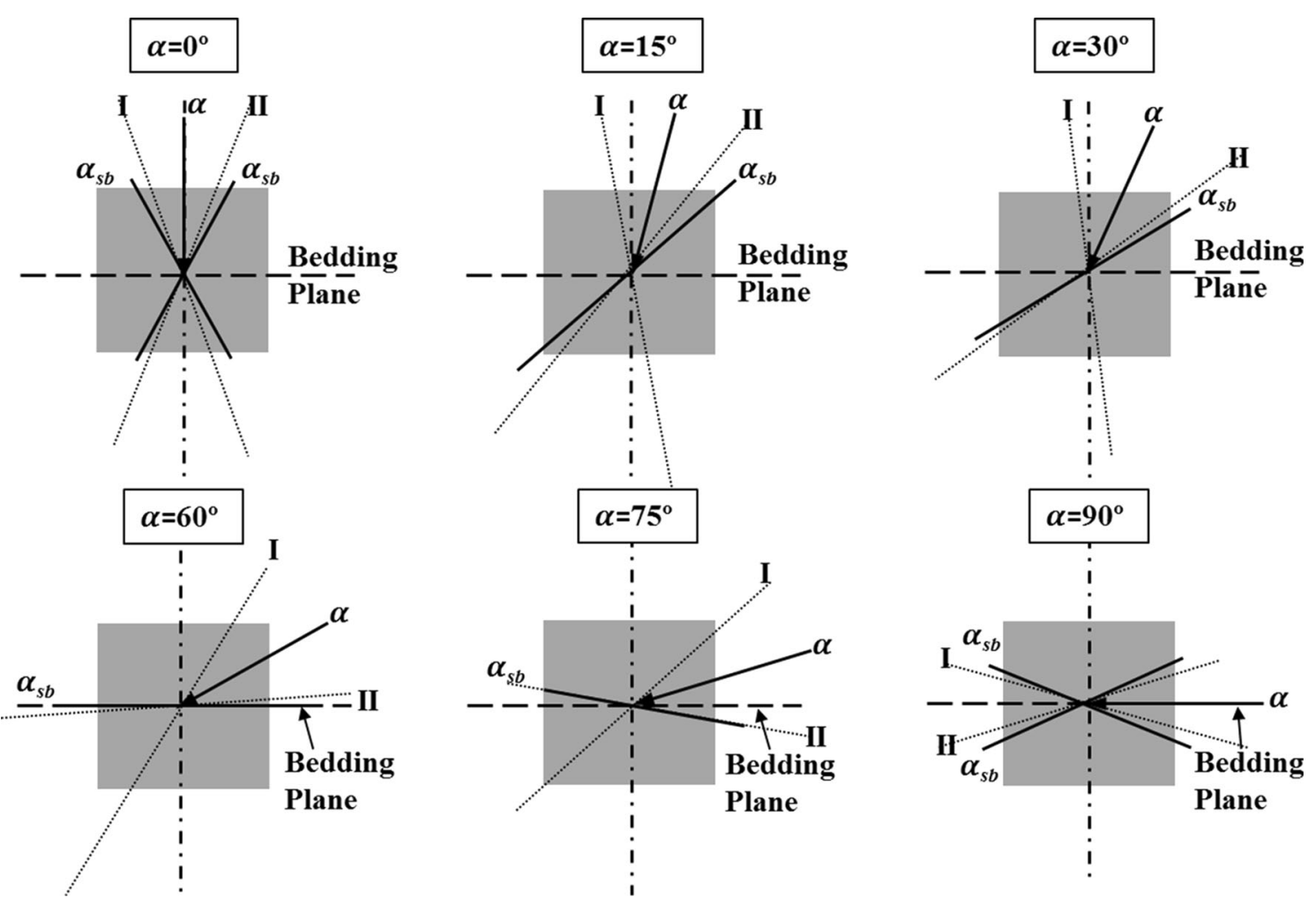

Fig. 18 Comparison of experimental shear band inclinations with theoretical predictions 
density and intermediate principal stress on the behaviour of Leighton Buzzard sand. Experiments have also been performed on glass beads to understand the effect of particle shape. Visual inspection of shear band formed at the end of testing has been presented. An attempt has also been made to explain the phenomenological observations of strength anisotropy and deformation non-coaxiality based on the recently acquired understanding in micromechanics. The major findings and conclusions can be summarized as follows:

- The effect of anisotropy produced during sample preparation is apparent in both deviatoric strain and volumetric strain responses of sand. Sand specimens subjected to preshearing to the peak stress were found to be softer and contracted more in the subsequent responses. For a given loading direction, the peak shear strength is relatively unaffected by preloading to the peak stress. However, the preshearing history does have a significant effect on the non-coaxiality of sand specimens. The change of void ratio imposed by drained preshearing cannot be used to explain the difference in the mechanical behaviours of the nonpresheared and presheared specimens. Therefore, it can be hypothesized that the peak effective stress ratio imposed during drained preshearing alters the behaviour of subsequent loading via another role, more likely changing the soil fabric as a result of stressinduced anisotropy. This hypothesis is consistent with previous investigations carried out under axisymmetric conditions [e.g. 8, 13-17, 20].

- It was also found that lower relative density and rounder particle shape of the assembly of granular materials tend to produce softer response, severer initial contraction and lower shear strength in monotonic shear. However, the effects of the particle shape and relative density on the non-coaxial behaviour of granular materials under monotonic shear were found to be less significant.

- Both, the loading direction and intermediate principal stress, have significant effects on the stress-strain behaviour of anisotropic sand under drained monotonic shear. For the same loading direction with constant $\alpha$ values, the shear strength of sand reduces and the volumetric compressibility increases with increasing values of $b$. The sand exhibits its highest peak friction angle at $b=0.5$ and $\alpha=0^{\circ}$ and the lowest at $b=1.0$ and $\alpha=75^{\circ}$. The influence of $b$-value on the noncoaxial behaviour of sand under monotonic shear is also evident. The lower the $b$-value, the higher the degree of non-coaxiality is induced.

- The initial anisotropy produced during sample preparation has pronounced effects on the formation of shear band in monotonic shear test. Different shear band patterns and inclination angles were observed from specimens with different loading directions. The obtained shear band inclinations were compared with theoretical predictions by Coulomb's theory. It was found that the inclinations of the shear bands at different loading directions can be predicted well by taking account of the relative direction of the mobilized planes to the bedding plane.

- The phenomenological observations of strength anisotropy and deformation non-coaxiality were explained by recently acquired micromechanical theories. Based on the established stress-force-fabric relationship, the strength anisotropy of granular materials was mainly due to the differences in the variation of the degrees of fabric anisotropy and force anisotropy at different loading directions. The degree of non-coaxiality was dependent on the relative direction, as well as the relative magnitude of the fabric anisotropy and the contact force anisotropy. As in monotonic shearing, the direction of force anisotropy is coaxial with the loading direction. Hence, the deformation non-coaxiality is the result of the principal directions of fabric anisotropy being deviated from the loading direction.

- Finally, it should be pointed out that anisotropic behaviour of Leighton Buzzard sand observed in HCA testing is more complex than that observed in conventional triaxial testing. Further study is still required to improve understanding of anisotropic behaviour of granular soils under generalized stress conditions.

Open Access This article is distributed under the terms of the Creative Commons Attribution 4.0 International License (http:// creativecommons.org/licenses/by/4.0/), which permits unrestricted use, distribution, and reproduction in any medium, provided you give appropriate credit to the original author(s) and the source, provide a link to the Creative Commons license, and indicate if changes were made.

\section{Appendix}

See Table 4. 
Table 4 Equations used to calculate stresses and strains [24]

\begin{tabular}{lll}
\hline Direction & Stress & Strain \\
\hline Vertical & $\bar{\sigma}_{\mathrm{z}}=\frac{W}{\pi\left(r_{\mathrm{o}}^{2}-r_{\mathrm{i}}^{2}\right)}+\frac{p_{\mathrm{o}} r_{0}^{2}-p_{\mathrm{i}} r_{\mathrm{i}}^{2}}{r_{\mathrm{o}}^{2}-r_{\mathrm{i}}^{2}}$ & $\bar{\varepsilon}_{\mathrm{z}}=\frac{w}{H}$ \\
Circumferential & $\bar{\sigma}_{\theta}=\frac{p_{\mathrm{o}} r_{\mathrm{o}}-p_{\mathrm{i}} r_{\mathrm{i}}}{r_{\mathrm{o}}-r_{\mathrm{i}}}$ & $\bar{\varepsilon}_{\theta}=-\frac{u_{\mathrm{o}}+u_{\mathrm{i}}}{r_{\mathrm{o}}+r_{\mathrm{i}}}$ \\
Radial & $\bar{\sigma}_{\mathrm{r}}=\frac{P_{\mathrm{o}} r_{\mathrm{o}}+P_{\mathrm{i}} r_{\mathrm{i}}}{r_{\mathrm{o}}+r_{\mathrm{i}}}$ & $\bar{\varepsilon}_{\mathrm{r}}=-\frac{u_{\mathrm{o}}-u_{\mathrm{i}}}{r_{\mathrm{o}}-r_{\mathrm{i}}}$ \\
Shear & $\bar{\sigma}_{\theta \mathrm{z}}=\frac{3 M_{\mathrm{T}}}{2 \pi\left(r_{\mathrm{o}}^{3}-r_{\mathrm{i}}^{3}\right)}$ & $\bar{\gamma}_{\theta \mathrm{z}}=\frac{2 \theta\left(r_{\mathrm{o}}^{3}-r_{\mathrm{i}}^{3}\right)}{3 H\left(r_{\mathrm{r}}^{2}-r_{\mathrm{i}}^{2}\right)}$ \\
Major principal & $\sigma_{1}=\frac{\sigma_{\mathrm{z}}+\sigma_{\theta}}{2}+\sqrt{\left(\frac{\sigma_{\mathrm{z}}-\sigma_{\theta}}{2}\right)^{2}+\tau_{\theta \mathrm{z}}^{2}}$ & $\varepsilon_{1}=\frac{\overline{\varepsilon_{z}}+\overline{\varepsilon_{\theta}}}{2}+\sqrt{\left(\frac{\overline{\varepsilon_{z}}-\overline{\varepsilon_{\theta}}}{2}\right)^{2}+\left(\frac{\overline{\gamma_{\theta}}}{2}\right)^{2}}$ \\
Intermediate principal & $\sigma_{2}=\sigma_{\mathrm{r}}$ & $\varepsilon_{2}=\overline{\varepsilon_{\mathrm{r}}}$ \\
Minor principal & $\sigma_{3}=\frac{\sigma_{\mathrm{z}}+\sigma_{\theta}}{2}-\sqrt{\left(\frac{\sigma_{\mathrm{z}}-\sigma_{\theta}}{2}\right)^{2}+\tau_{\theta \mathrm{z}}^{2}}$ & $\varepsilon_{3}=\frac{\overline{\varepsilon_{z}}+\overline{\varepsilon_{\theta}}}{2}-\sqrt{\left(\frac{\overline{\varepsilon_{z}}-\overline{\varepsilon_{\theta}}}{2}\right)^{2}+\left(\frac{\overline{\gamma_{\theta z}}}{2}\right)^{2}}$ \\
Volumetric & $p=\frac{\sigma_{1}+\sigma_{2}+\sigma_{3}}{3}$ & $\varepsilon_{\mathrm{v}}=\varepsilon_{1}+\varepsilon_{2}+\varepsilon_{3}$ \\
Deviatoric & $q=\sqrt{\frac{1}{2}\left\{\left(\sigma_{1}-\sigma_{2}\right)^{2}+\left(\sigma_{2}-\sigma_{3}\right)^{2}+\left(\sigma_{2}-\sigma_{3}\right)^{2}\right\}}$ & $\varepsilon_{\mathrm{q}}=\sqrt{\frac{2}{9}\left\{\left(\varepsilon_{1}-\varepsilon_{2}\right)^{2}+\left(\varepsilon_{2}-\varepsilon_{3}\right)^{2}+\left(\varepsilon_{3}-\varepsilon_{1}\right)^{2}\right\}}$ \\
\hline
\end{tabular}

$r_{\mathrm{o}}$ outer radius, $r_{\mathrm{i}}$ inner radius, $H$ height of specimen, $w$ axial deformation, $u_{\mathrm{o}}$ outer radius deformation, $u_{\mathrm{i}}$ inner radius deformation, $\theta$ torsional deformation

\section{References}

1. Abelev A, Lade PV (2004) Characterization of failure in cross anisotropic soils. J Eng Mech 130(5):599-606

2. Alshibli AK, Sture S (2000) Shear band formation in plane strain experiments of sand. $\mathrm{J}$ Geotech Geoenviron Eng ASCE 126(6):495-503

3. Arthur RF, Menzies BK (1972) Inherent anisotropy in sand. Geotechnique 22(1):115-131

4. Arthur JRF, Bekenstein S, Germaine JT, Ladd CC (1981) Stress path tests with controlled rotation of principal stress direction. Lab Shear Strength Soil Am Soc Test Mater STP 740:516-540

5. Barreto D, O'Sullivan C (2012) The influence of inter-particle friction and the intermediate stress ratio on soil response under generalised stress conditions. Granul Matter 14(4):505-521

6. Been K, Jefferies MG (1985) A state parameter for sands. Géotechnique 35(2):99-112

7. Bésuelle P, Viggiani G, Lenoir N, Desrues J, Bornert M (2006) $\mathrm{X}$-ray micro CT for studying strain localization in clay rocks under triaxial compression. Keynote paper. In: Desrues J et al (eds) Advances in X-ray tomography for geomaterials. ISTE, London, pp 35-52

8. Bobei DC, Wanatowski D, Rahman MM, Lo SR, Gnanendran CT (2013) The effect of drained pre-shearing on the undrained behaviour of loose sand with a small amount of fines. Acta Geotech 8(3):311-322. doi:10.1007/s11440-012-0195-2

9. Cai YY, Yu HS, Wanatowski D, Li X (2013) Non-coaxial behavior of sand under various stress paths. J Geotech Geoenviron Eng 139(8):1381-1395

10. Casagrande A, Carrillo N (1944) Shear failure on anisotropic materials. Proc Boston Soc Civil Eng 31:74-87

11. Coulomb CA (1773) Sur l'application des règles des maximis et minimis à quèlques problèmes de statique relatifs à l'architecture. Mémoires de Mathématique et de Physique. Acad R Sci 7:343-382

12. Cundall PA, Strack ODL (1979) A discrete numerical model for granular assemblies. Géotechnique 29(1):47-65
13. Di Prisco C, Matiotti R, Nova R (1995) Theoretical investigation of the undrained stability of shallow submerged slopes. Geotechnique 45(3):479-496

14. Doanh T, Ibraim E, Matiotti R (1997) Undrained instability of very loose Hostun sand in triaxial compression and extension. Part 1: experimental observations. Mech Cohes Frict Mater 2:47-70

15. Doanh T, Dubujet Ph, Touron T (2010) Exploring the undrained induced anisotropy of Hostun RF loose sand. Acta Geotech 5(4):239-256

16. Doanh T, Finge Z, Boucq S (2012) Effects of previous deviatoric strain histories on the undrained behavior of Hostun RF loose sand. Geotech Geol Eng 30(4):697-712

17. Doanh T, Dubujet PH, Protiere X (2013) On the undrained straininduced anisotropy of loose sand. Acta Geotech 8(3):293-309

18. Doanh T, Hoang MT, Roux JN, Dequeker C (2013) Stick-slip behaviour of model granular materials in drained triaxial compression. Granul Matter 15(1):1-23

19. Finge Z, Doanh T, Dubujet PH (2006) Undrained anisotropy of Hostun RF loose sand: new experimental investigations. Can Geotech J 43:1195-1212

20. Gajo A, Piffer L (1999) The effects of preloading history on the undrained behaviour of saturated loose sand. Soils Found $39(6): 43-54$

21. Gutierrez M, Ishihara K, Towhata I (1991) Flow theory for sand during rotation of principal stress direction. Soils Found 31(4):121-132

22. Hareb T, Doanh T (2012) Probing into the strain induced anisotropy of Hostun RF loose sand. Granul Matter 14(5):589-605

23. Haruyama M (1981) Anisotropic deformation-strength properties of an assembly of spherical particles under three dimensional stresses. Soils Found 21(4):41-55

24. Hight DW, Gens A, Symes MJ (1983) The development of a new hollow cylinder apparatus for investigating the effects of principal stress rotation in soil. Geotechnique 33(4):355-383

25. Ishihara K, Okada S (1978) Effects of stress history on cyclic behavior of sand. Soils Found 18(4):31-45 
26. Ishihara K, Okada S (1982) Effects of large pre-shearing on cyclic behavior of sand. Soils Found 22(3):109-125

27. Kumruzzaman MD, Yin JH (2010) Influences of principal stress direction and intermediate principal stress on the stress-strainstrength behaviour of completely decomposed granite. Can Geotech J 47(2):164-179

28. Kallstenius T, Bergau W (1961) Research on the texture of granular masses. In: Proceedings of the 5th international conference on soil mechanics and foundation engineering, vol 1, pp $165-170$

29. Kuwano R (1999) The stiffness and yielding anisotropy of sand. $\mathrm{PhD}$ thesis, Imperial College, London, UK

30. Lade PV, Duncan JM (1973) Cubical triaxial tests on cohesionless soil. J Soil Mech Found Div ASCE 99(10):793-811

31. Lade PV, Prabucki MJ (1995) Softening and preshearing effects in sand. Soils Found 35(4):93-104

32. Lade PV, Nam J, Hong WP (2008) Shear banding and crossanisotropic behaviour observed in laboratory sand tests with stress rotation. Can Geotech J 45:74-84

33. Lashkari A, Latifi M (2008) A non-coaxial constitutive model for sand deformation under rotation of principal stress axes. Int $\mathbf{J}$ Numer Anal Meth Geomech 32(9):1051-1086

34. Li XS, Dafalias YF (2004) A constitutive framework for anisotropic sand including non-proportional loading. Geotechnique 54(1):41-51

35. Li X, Li XS (2009) Micro-macro quantification of the internal structure of granular material. J Eng Mech ASCE 135(7):641-656

36. Li X, Yu HS (2009) Influence of loading direction on the behaviour of anisotropic granular materials. Int $\mathrm{J}$ Eng Sci 47:1284-1296

37. Li X, Yu HS (2014) Fabric, force and strength anisotropies in granular materials: a micromechanical insight. Acta Mech 225(8):2345-2362

38. Li X, Yu HS (2015) Particle scale insight into deformation noncoaxiality of granular materials. Int J Geomech 15(4):04014061. doi:10.1061/(ASCE)GM.1943-5622.0000338

39. Miura S, Toki S (1984) Anisotropy in mechanical properties and its simulation of sands sampled from natural deposits. Soils Found 24(3):69-84

40. Miura S, Toki S (1986) Deformations prediction for anisotropic sand during the rotation of principal stress axes. Soils Found 26(3):42-56

41. Miura K, Miura S, Toki S (1986) Deformation behavior of anisotropic dense sand under principal stress axes rotation. Soils Found 26(1):36-52

42. Nakata Y, Hyodo M, Murata H, Itakura S, Yamada Y (1997) Flow deformation of sands subjected to principal stress rotation. Mem Fac Eng Yamaguchi Univ 48(1):57-64

43. Nakata Y, Hyodo M, Murata H, Yasufuku N (1998) Flow deformation of sands subjected to principal stress rotation. Soils Found 38(3):115-128

44. Ochiai H, Lade PV (1983) Three-dimensional behaviour of sand with anisotropic fabric. J Geotech Eng 109(10):1313-1328

45. Oda M, Iwashita K (1999) Mechanics of granular materials: an introduction. CRC Press, Boca Raton

46. Oda M, Konishi J (1974) Microscopic deformation mechanism of granular material in simple shear. Soils Found 14(4):25-38

47. Oda M, Konishi J (1974) Rotation of principal stresses in granular material during simple shear. Soils Found 14(4):39-53

48. Oda M, Isao K, Toshio H (1978) Experimental study of anisotropic shear strength of sand by plane strain test. Soils Found 18(1):25-38

49. Oda M, Nemat-Naser S, Konishi J (1985) Stress-induced anisotropy in granular masses. Soils Found 25(3):85-97
50. Phillips AB, May PH (1967) A form of anisotropy in granular media. Special Task Report, Dept. of Civil and Municipal Engineering, Univ. College, London

51. Poorooshasb HB, Holubec I, Sherbourne AN (1966) Yielding and flow of sand in triaxial compression: part 1. Can Geotech J 3(4):179-190

52. Poorooshasb HB, Holubec I, Sherbourne AN (1967) Yielding and flow of sand in triaxial compression: part 2 and 3. Can Geotech $\mathbf{J}$ 4(4):376-397

53. Roscoe KH, Bassett RH, Cole ERL (1967) Principal axes observed during simple shear of a sand. In: Proceedings of the 4th European conference on soil mechanics and foundation engineering, Oslo, pp 231-237

54. Reades DW, Green GE (1976) Independent stress control and triaxial extension tests on sand. Géotechnique 26(4):551-576

55. Rolo R (2003) The anisotropic stress-strain-strength behaviour of brittle sediments. PhD thesis, Imperial College, London, UK

56. Rothenburg L, Bathurst RJ (1989) Analytical study of induced anisotropy in idealized granular materials. Géotechnique 39(4):601-614

57. Sayao ASFJ, Vaid YP (1996) Influence of intermediate principal stress on the deformation response of sand. Can Geotech $\mathbf{J}$ 33:822-828

58. Symes MJ, Hight DW, Gens A (1982) Investigating anisotropy and the effects of principal stress rotation and of the intermediate principal stress using a hollow cylinder apparatus. In: IUTAM conference on deformation and failure of granular materials, pp 441-449

59. Symes MJ, Gens A, Hight DW (1988) Drained principal stress rotation in saturated sand. Geotechnique 38(1):59-81

60. Sivathayalan S, Vaid YP (1998) Truly undrained response of granular soils with no membrane penetration effects. Can Geotech J 35:730-739

61. Takemura T, Takahashi M, Oda M, Hirai H, Murakoshi A, Miura M (2007) Three-dimensional fabric analysis for anisotropic material using multi-directional scanning line-application to X-ray CT image. Mater Trans 48(6):1173-1178

62. Tatsuoka F, Ishihara K (1974) Yielding of sand in triaxial compression. Soils Found 14(2):63-76

63. Tatsuoka F, Nakamura S, Huang CC, Tani K (1990) Strength anisotropy and shear band direction in plane strain tests of sand. Soils Found 30(1):35-54

64. Tsutsumi S, Hashiguchi K (2005) General non-proportional loading behaviour of soils. Int J Plast 22:826-857

65. Thornton C (2000) Numerical simulation of deviatoric shear deformation of granular media. Géotechnique 50(1):43-53

66. Thornton C, Zhang L (2010) On the evolution of stress and microstructure during general 3D deviatoric straining of granular media. Géotechnique 60(5):333-341

67. Vaid YP, Sayao ASF, Hou E, Negussey D (1990) Generalised stress-path dependent behaviour with a new hollow cylinder torsional apparatus. Can Geotech J 27:601-616

68. Vaid YP, Chung EKF, Kuerbis RH (1989) Preshearing and undrained response of sand. Soils Found 29(4):49-61

69. Wanatowski D, Chu J (2006) Stress-strain behavior of a granular fill measured by anew plane-strain apparatus. Geotech Test J 29(2):149-157

70. Wanatowski D, Chu J (2008) Effect of specimen preparation method on the stress-strain behavior of sand in plane-strain compression tests. Geotech Test J 31(4):308-320

71. Wong RKS, Arthur RF (1985) Induced and inherent anisotropy in sand. Geotechnique 35(4):471-481

72. Yamada Y, Ishihara K (1979) Anisotropic deformation characteristics of sand under three dimensional stress conditions. Soils Found 19(2):79-94 
73. Yang YM, Yu HS (2012) A kinematic hardening soil model considering the principal stress rotation. Int J Numer Anal Meth Geomech 37(13):2106-2134

74. Yu HS (2008) Non-coaxial theories of plasticity for granular materials. In: The 12th international conference of international association for computer methods and advances in geomechanics (IACMAG), Goa, India

75. Yu HS, Yang L-T, Li X, Wanatowski D (2015) Experimental investigation on the deformation characteristics of granular materials under drained rotational shear. Geomech Geoeng. doi:10.1080/17486025.2015.1006267

76. Zhu HN, Mehrabadi MM, Massoudi M (2006) Incorporating the effects of fabric in the dilatant double shearing model for planar deformation of granular materials. Int J Plast 22:628-653

77. Zhu HN, Mehrabadi MM, Massoudi M (2006) Three-dimensional constitutive relations for granular materials based on the dilatant double shearing mechanism and the concept of fabric. Int J Plast 22:826-857 